\title{
Effect of Environment on Activation and Sorption of Getter Alloys and Multilayers for Hybrid Wafer-level Vacuum Packaging
}

\author{
Alain Bosseboeuf, ${ }^{1 *}$ Sylvain Lemettre, ${ }^{1}$ Ming Wu, ${ }^{1,2}$ Johan Moulin, ${ }^{1}$ Philippe Coste, ${ }^{1}$ \\ Clément Bessouet, ${ }^{1}$ Sana Hammami, ${ }^{1}$ Charles Renard, ${ }^{1}$ and Laetitia Vincent ${ }^{1}$ \\ ${ }^{1}$ Center for Nanoscience and Nanotechnology (C2N), CNRS, Univ. Paris-Sud, Univ. Paris-Saclay, \\ 10 Boulevard Thomas Gobert, 91120 Palaiseau, France \\ ${ }^{2}$ Department of Microelectronics, Soochow University, Suzhou 215006, China
}

(Received January 25, 2019; accepted May 2, 2019)

Keywords: getter films, vacuum packaging, MEMS, outgassing, activation, sorption

A large set of micro- and nanodevices requires hybrid vacuum packaging at the wafer level to optimize their performance and lifetime. When the temperature of the packaging fabrication process is limited, getter films must be integrated into the packaging cavity to obtain a low and sustainable pressure. In this paper, gas generation and residual gases inside a wafer-level package, as well as the main getter alloy films and multilayers investigated previously, are reviewed. An emphasis is put on the effect of a gaseous environment on the physicochemical mechanisms involved in getter film activation and gas sorption. A large outgassing occurs during the packaging fabrication process. It produces a gas load larger than or similar to that generated during the entire lifetime of the device at room temperature. The resulting partial pressures of gases in a micropackage are quite different from those found in ultrahigh vacuum during characterization by surface analysis techniques and when getter films are used in accelerators. Consequently, in micropackages, activation and sorption steps can no longer be analyzed separately and surface oxidation and/or oxygen bulk diffusion during activation should be taken into account. It is thus recommended to use and develop complementary characterization techniques that enable the investigation of surface and bulk phenomena at various temperatures, pressures, and gas mixtures for the assessment of getter films for vacuum packaging.

\section{Introduction}

A sustainable vacuum or well-controlled environment is required for various micro/ nanodevices to reach optimal performance and increase their lifetime. Some well-known examples are electromechanical or optomechanical micro/nanoresonators used in quartz or $\mathrm{Si}$ MEMS oscillators, ${ }^{(1)}$ in physical resonant micro/nanosensors, ${ }^{(2,3)}$ in radio-frequency filters, ${ }^{(4)}$ in optical scanners, ${ }^{(5)}$ in mass sensors with embedded fluidic microchannels, ${ }^{(6)}$ or in quantum

*Corresponding author: e-mail: alain.bosseboeuf@c2n.upsaclay.fr

https://doi.org/10.18494/SAM.2019.2312 
devices. $^{(7)}$ For these devices, a low ambient pressure is necessary to avoid squeeze ${ }^{(8,9)}$ and slide $^{(10)}$ film vibration damping that can largely degrade the resonance quality factor and thus the device sensitivity, resolution, and stability. This is achieved for pressures typically below $10^{-3}-10^{-2}$ mbar for microresonators and for pressures up to $\sim 20$ mbar for nanoresonators. ${ }^{(11)}$ For other MEMS or miniaturized devices such as RF switches, nonresonant accelerometers or miniaturized atomic clocks, a much higher ambient pressure (1-100 mbar) of inert or specific gas is used to control damping or gas absorption, but a stable pressure and a high gas purity must be maintained. ${ }^{(12,13)}$ For thermal devices, ${ }^{(14)}$ electrothermal devices (e.g., microheaters and microactuators), and infrared sensors, a low pressure (for example, $<10^{-3}$ mbar for highperformance uncooled microbolometers) ${ }^{(15)}$ is also required to prevent thermal losses caused by air convection and conduction. Finally, vacuum is also needed inside the reference cavity of nonresonant absolute pressure sensors ${ }^{(17)}$ as well as for tunneling devices, field emitter devices, ${ }^{(18-20)}$ and miniaturized X-Ray sources ${ }^{(21)}$ to avoid gas absorption, scattering, and contamination. A large number of miniaturized devices are thus concerned by the development of vacuum packaging technologies.

Such a vacuum environment is achieved by integrating the micro/nanodevice in a highly hermetic vacuum encapsulation. To lower the packaging cost that represents a large part of the final cost for MEMS devices, vacuum packaging at the wafer level (WLP) is increasingly used. A getter-less vacuum packaging of MEMS devices can be realized, ${ }^{(13,14,22,24,26-36)}$ but it typically requires high-temperature $\left(400-1100{ }^{\circ} \mathrm{C}\right)$ baking and sealing steps, and/or a long outgassing step; otherwise, it leads to a relatively high internal pressure (Table 1). For example, an internal pressure down to $10^{-3}$ mbar can be achieved by the epi-seal fabrication process ${ }^{(24)}$ but the process involves annealing at $1100{ }^{\circ} \mathrm{C}$ for $8 \mathrm{~h}$ after bonding, high-temperature baking, at $1150{ }^{\circ} \mathrm{C}$ for cavity sealing by hydrogen annealing and silicon migration, or cavity sealing by depositing epitaxial silicon at $1080{ }^{\circ} \mathrm{C}$. Such high-temperature steps are, for example, not compatible with devices fabricated by CMOS, III-V or quartz technologies or devices

Table 1

Residual pressures measured inside MEMS hermetic packages without getter.

\begin{tabular}{lcccc}
\hline $\begin{array}{l}\text { Residual } \\
\text { pressure after } \\
\text { sealing (mbar) }\end{array}$ & $\begin{array}{c}\text { Cavity volume } \\
(\mu \mathrm{L})\end{array}$ & Sealing technique & $\begin{array}{c}\text { Maximum } \\
\text { sealing } \\
\text { temperature }\left({ }^{\circ} \mathrm{C}\right)\end{array}$ & Reference(s) \\
\hline 23.8 & 0.09 & Silicon direct bonding & 400 & 26 \\
6,10 & $8, ?$ & Au-Si eutectic bonding & 390 & 27,28 \\
3.6 & 0.54 & Anodic bonding & 400 & 26 \\
3 & $5 ?$ & Au-In TLP bonding & 200 & 29 \\
2.3 & 7.5 & Anodic bonding & $\sim 400$ & 13 \\
$<1$ & 1.3 & Cu-Cu thermocompression & 250 & 30 \\
0.7 & $?$ & Anodic bonding & 400 & 31 \\
$0.67,1.2$ & $?$ & Au-Sn eutectic bonding & $380, \sim 300$ & 32,33 \\
0.4 & $?$ & Anodic bonding & 450 & 34 \\
0.2 & $?$ & Al-Ge eutectic bonding & 430 & 35 \\
$5 \times 10^{-2}$ & 0.7 & Anodic bonding & 400 & 36 \\
$2.2 \times 10^{-2}$ & 4.8 & Si direct fusion bonding & High & 22 \\
$10^{-3}$ & $?$ & Epi-poly sealing or sealing by & $1080-1100$ & 24 \\
& & $\mathrm{H}_{2}$ annealing and Si migration & & \\
\hline
\end{tabular}


involving materials with large differences in the coefficient of thermal expansion or prone to interdiffusion. To reduce the thermal budget while keeping a low internal pressure, and to extend the application range of packaging technologies, one of the common methods used is the integration of a nonevaporable getter (NEG) material (i.e., not in situ evaporated) into the package cavity (Fig. 1). These processes use a highly hermetic bonding process (anodic, glass frit or metallic) of a cap die/wafer on the device wafer. ${ }^{(37)}$ Eventually, to limit the effect of outgassing during bonding, the cap can include a small aperture that is sealed only after bonding by film deposition, by an indium ball, or by a solder alloy reflow. ${ }^{(22,24)}$

It was clearly demonstrated that NEG materials, once thermally activated, can pump by chemisorption most of the gases except noble gases inside the package cavity, and enable us to reach and maintain a good vacuum level. The NEG material is usually located at the bottom of the cap wafer cavity, but it can also be at the periphery of the device or cap wafer, ${ }^{(37)}$ in an adjacent cavity, ${ }^{(17,38)}$ notably when the cap is used as an optical window, and obviously at any other available places. Getter materials in the form of porous pills are still sometimes used, ${ }^{(13,16)}$ but there are now widely replaced by getter materials in thin film form to limit their size as well as particle generation, and to allow their integration by batch processing.

The goals of this study are to reconsider the getter film pumping requirements and gaseous environment in the packaging cavity during processing and the device lifetime, and to discuss the effect of this environment on the activation and sorption mechanisms of alloy and multilayer getters, and on their characterization.

\section{Gas Loading and Getter Pumping Requirements in Micropackages}

\subsection{Gas loading sources and simple modelling}

The pressure inside a cavity of a micropackage tends to rapidly increase with time because of (i) the outgassing of sealing rings, device materials, and internal walls during die/wafer bonding, getter thermal activation, thermal reliability tests, and the packaged device lifetime (10-20 years), (ii) real and virtual package air leaks, and (iii) gas permeation through sealing rings, $\mathrm{SiO}_{2}$ or glass films, caps, and substrates.

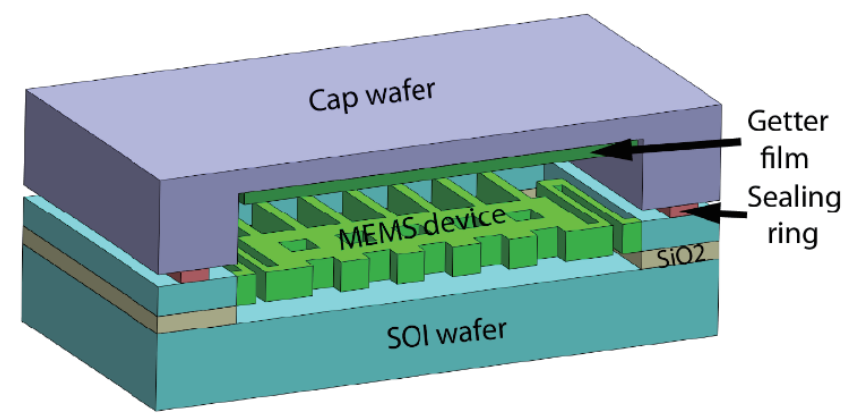

Fig. 1. (Color online) Cross-sectional simplified drawing of hybrid vacuum packaging of a SOI MEMS device based on low-temperature bonding of a cap wafer/die integrating a getter material in the cavity. 
These phenomena impose the getter film pumping rate required to reach and maintain the desired vacuum level. The equation describing the variation in the internal partial pressure $P_{\text {int }}$ of a given gas inside a packaging cavity of volume $V$ is, in pressure-volume units,

$$
V d P_{\text {int }} / d t=\sum_{j} \pi_{j} A_{j}+L_{T o t}+\sum_{i} A_{i} \tau_{i}-P_{i n t} S_{g} A_{g}
$$

where $\pi_{j}$ is the rate of gas generation by permeation per unit area of walls with area $A_{j}, L_{T o t}$ the total leak rate, $A_{i}$ the area of internal surfaces composed of material $i$ and $\tau_{i}$ their outgassing rate per unit surface, $S_{g}$ the pumping rate per unit area of the getter film, and $A_{g}$ its area.

The permeation rate per unit area of a wall depends on the difference between the external pressure $P_{\text {ext }}$ and the internal pressure $P_{\text {int }}$, and on the wall thickness $d$ as

$$
\pi_{j}=K_{i}\left(P_{\text {ext }}-P_{\text {int }}(t)\right) / d
$$

where the constant $K_{i}$ is thermally activated.

Likewise, the leak rate in the molecular regime is proportional to the differential pressure.

$$
L_{\text {Tot }}=B\left(P_{\text {ext }}-P_{\text {int }}(t)\right)
$$

For low internal pressures, the rates of gas generation by leaks and permeation are approximately constant.

The net outgassing rate depends in a complex way on gas surface coverage, heating rate, diffusion, re-adsorption, and gas trapping characteristics. ${ }^{(39)}$ It globally increases during temperature rise, and then, after some time (typically $1 \mathrm{~h}$ in vacuum technology), the outgassing rate is a decreasing function of time and can be approximated by a power law. ${ }^{(40)}$

$$
\tau_{i}=\tau_{1 \mathrm{hi} 0}(t / 1 h)^{-\alpha}
$$

Here, $\tau_{1 h i 0}$ is the outgassing rate of gas $i$ after $1 \mathrm{~h}, \alpha \approx 1$ for most gases and metallic surfaces, and $\alpha=1 / 2$ for diffusion-controlled outgassing from the bulk (often considered for hydrogen).

Both permeation and outgassing are thermally activated and thus are highly variable with temperature. In the ideal case of negligible outgassing, during the package lifetime at room temperature, the internal pressure would increase from the initial pressure $P_{\text {int }}(0)$ as

$$
P_{\text {int }}(t)=P_{\text {int }}(0)+\left[P_{\text {ext }}-P_{\text {int }}(0)\right]\left[1-\exp \left(-\frac{\sum_{j} \frac{K_{j}}{d} A_{j}+B}{V} t\right)\right]
$$


If the internal pressure remains very low with respect to the external pressure, it approximately increases linearly with time as

$$
P_{\text {int }}(t) \approx P_{\text {int }}(0)+\frac{\sum_{j} \pi_{j} A_{j}+L_{T o t}}{V} t .
$$

A simple calculation shows that even with a total gas generation rate as low as $10^{-15}$ $\mathrm{atm} \cdot \mathrm{cm}^{3} \cdot \mathrm{s}^{-1}$, the pressure variation inside a $1 \mu \mathrm{L}$ package would increase by $0.3 \mathrm{mbar}$ after ten years. This clearly demonstrates that gas pumping with a getter film is required to maintain a low pressure for the entire device lifetime.

\subsection{Gas loading in a wafer-level package}

To give an idea of the contribution of each gas generation term during processing and the device lifetime, and the resulting getter pumping requirements, let us consider as an example the case of an $8 \times 6 \mathrm{~mm}^{2} \mathrm{Si}$ or glass cap with a $10-\mu \mathrm{m}$-deep cavity bonded at $250{ }^{\circ} \mathrm{C}$ to a $\mathrm{Si}$ MEMS die with a metallic sealing ring and a getter film covering the bottom surface of the cap. This package volume $(\sim 0.5 \mu \mathrm{L})$ and surface-to-volume ratio $\left(5 \times 10^{-4} \mathrm{~cm}^{-1}\right)$ correspond to a relatively favorable case as smaller package volumes down to $1 \mathrm{~nL}$ are also common.

The gas permeability of silicon and metals is only significant for light gases $\left(\mathrm{H}_{2}\right.$ and $\left.\mathrm{He}\right)$ and at a very high temperature. ${ }^{(41,42)}$ Thus, for a package technology without polymer materials, gas permeation mainly occurs through existing glass or silica layers or windows, ${ }^{(43,44)}$ and through bonding interfaces or thin parts. ${ }^{(45)}$ The permeation velocity $\mathrm{K}$ of He through borosilicate glass at $250{ }^{\circ} \mathrm{C}$ is about $2 \times 10^{-10} \mathrm{~cm}^{3}$ per $\mathrm{cm}^{2} \cdot \mathrm{s}^{-1} \cdot \mathrm{atm}^{-1} \cdot \mu \mathrm{m}^{-1}$, which is about 10 -fold lower than that of hydrogen. ${ }^{(43)}$ The differential pressures of $\mathrm{He}$ and $\mathrm{H}_{2}$ during vacuum bonding, and during getter film activation under vacuum or controlled atmosphere at atmospheric pressure, are normally low $\left(<10^{-1}\right.$ mbar). For the considered cap dimensions and a cap made of 500- $\mu \mathrm{m}$-thick borosilicate glass, Eq. 2 shows that the permeation rates of $\mathrm{He}$ and $\mathrm{H}_{2}$ are consequently also very low (for example, $2 \times 10^{-17} \mathrm{~atm} \cdot \mathrm{cm}^{3} \cdot \mathrm{s}^{-1}$ for He). The permeation rates during the device lifetime at room temperature are even lower because the partial pressures of $\mathrm{He}$ and $\mathrm{H}_{2}$ in air at atmospheric pressure are $5.33 \times 10^{-3}$ and $5.06 \times 10^{-5} \mathrm{mbar}$, respectively (values at the sea level), and the permeation velocities are about 2 orders of magnitude lower than those at $250{ }^{\circ} \mathrm{C} .{ }^{(43)}$ In the case of hydrogen, higher permeation rates can occur during temperature-humidity reliability tests because the dissociative chemisorption of hydrogen on external surfaces provides an additional hydrogen source for permeation. To limit $\mathrm{He}$ and $\mathrm{H}_{2}$ intake by permeation, it is thus better to coat glass and silica external or internal areas with a material of low $\mathrm{He}$ and $\mathrm{H}_{2}$ permeabilities.

With state-of-the-art highly hermetic bonding or welding technologies, the total leak rate of vacuum packages, $L_{T o t}$, is in the $10^{-15}-10^{-12} \mathrm{~atm} \cdot \mathrm{cm}^{3} \cdot \mathrm{s}^{-1}$ range, ${ }^{(23,30,46,47)}$ but leak rates up to a few $10^{-8} \mathrm{~atm} \cdot \mathrm{cm}^{3} \cdot \mathrm{s}^{-1}$ remain also common notably when no liquid phase is involved in the bonding process. 
In any case, there are always some amounts of $\mathrm{He}$ and $\mathrm{H}_{2}$ entering a wafer-level package by permeation through dielectric materials ${ }^{(45)}$ and by leaks whatever the bonding technology. $\mathrm{He}$, similarly to other rare gases, is not pumped by getter materials, and $\mathrm{H}_{2}$ sorption by getter materials is usually reversible. Consequently, $\mathrm{He}$ and $\mathrm{H}_{2}$ intakes by permeation and leaks can contribute to partial pressures of $\mathrm{He}$ and $\mathrm{H}_{2}$ typically detected in wafer-level packages.

Outgassing inside a package is difficult to evaluate because published outgassing experiments of silicon, MEMS materials, and WLP sealing materials are very scarce $^{(12,26,48,50,51)}$ and only few of them allow the estimation of the outgassing rate per unit surface. In addition, the outgassing rate of a given material can vary by several orders of magnitude according to elaboration and cleaning conditions, pumping time, gas, and outgassing temperature. Monocrystalline silicon has a high purity and is dense without grain boundaries. Its outgassing is mainly due to surface contamination by molecular compounds and water vapor. Water vapor should readily be desorbed during temperature rise up to the wafer/die bonding temperature, and, if well cleaned, single crystal silicon parts should not desorb large amounts of hydrocarbons. ${ }^{(52)}$ It is therefore expected that internal silicon surfaces generate a negligible long-term outgassing when compared with polysilicon, ${ }^{(51)}$ polycrystalline metals, silica, silicon nitride and other layers of the device and sealing rings. From the investigations of Savornin et al., ${ }^{(49)}$ the total outgassing rate of silica films at $250{ }^{\circ} \mathrm{C}$ is approximately in the $1 \times 10^{-8}$ $-6.6 \times 10^{-7} \mathrm{~atm} \cdot \mathrm{cm}^{3} \cdot \mathrm{s}^{-1} \cdot \mathrm{cm}^{-2}$ range and is mainly due to hydrogen, nitrogen, hydrocarbons (notably methane), and $\mathrm{CO}_{2}$. Thus, for the rough estimation of the pumping requirements and gaseous environment of the getter film during processing, let us consider the outgassing rate of the device area to be equal to $6.6 \times 10^{-7} \mathrm{~atm} \cdot \mathrm{cm}^{3} \cdot \mathrm{s}^{-1} \cdot \mathrm{cm}^{-2}$ at $250{ }^{\circ} \mathrm{C}$. For the package dimensions considered above with a device area of around $0.5 \mathrm{~cm}^{2}$, the total outgassing rate would be around 3.3 $\times 10^{-7} \mathrm{~atm} \cdot \mathrm{cm}^{3} \cdot \mathrm{s}^{-1}$. This value is actually much lower than the outgassing rates measured by Tominetti and Della Porta ${ }^{(12)}$ during the bonding of a MEMS package for automotive application. In addition, in the case of the anodic bonding of glass on $\mathrm{Si}$, a large amount of $\mathrm{O}_{2}$ is known to be released ${ }^{(26)}$ and electroplated or solder sealing rings are also a significant source of outgassing. Thus, we can safely consider that the outgassing rate is much higher than stateof-the-art total leak and permeation rates. This clearly shows that outgassing is the main source of gas generation inside a micropackage notably because an enhanced outgassing occurs during wafer bonding and the thermal activation of the getter film. In addition, some significant outgassing could also occur during thermal cycles performed for reliability tests. ${ }^{(27)}$

Thus, starting from the initial pressure $P_{\text {int }}(0)$ when the package cavity becomes hermetic during wafer bonding, no pressure rise would occur if the getter film initial pumping rate of the released gases is higher than the outgassing rate (see Eq. 1).

For the package dimensions considered above, an initial pressure of $10^{-3} \mathrm{mbar}\left(\sim 10^{-6} \mathrm{~atm}\right)$, and a temperature of $250{ }^{\circ} \mathrm{C}$, Eq. 1 shows that an initial pumping rate of $0.3 \mathrm{~cm}^{3} \cdot \mathrm{s}^{-1}$ would be needed. This can be compatible with a $0.5 \mathrm{~cm}^{2}$ getter film. However, the maximum sorption capacity of getter films is usually low $\left(10^{-6}-10^{-4} \mathrm{~atm} \cdot \mathrm{cm}^{3} \cdot \mathrm{cm}^{-2}\right)^{(53-57)}$ and the getter films would be very rapidly saturated in a few seconds to a few minutes. An efficient outgassing of the cap and device wafer is thus mandatory before sealing to reduce the outgassing rate by 2 orders of magnitude or more. Outgassing during getter film activation can also be reduced by 
local heating through joule heating, by a laser ${ }^{(51)}$ or by any other means. Then, after cooling to room temperature, because outgassing is thermally activated, the outgassing rate is expected to largely decrease. There is no data on the activation energy of the outgassing of MEMS materials but, to give an idea, the stainless steel outgassing rate at room temperature is 300 times lower than that at $250{ }^{\circ} \mathrm{C}$. Thus, if we assume a similar decrease for packaging and device materials, a decrease in outgassing rate by two orders of magnitude or more is expected after cooling. In addition, the outgassing rate is time-dependent (see Eq. 4) and can decrease by orders of magnitude in few days. Therefore, after some days and during the subsequent package lifetime, the outgassing and leak rates might become similar and can both limit the vacuum level. A getter film pumping rate in the range of a few $10^{-4} \mathrm{~cm}^{3} \cdot \mathrm{s}^{-1}$ could then be sufficient for maintaining the required vacuum level during the device lifetime at room temperature.

Several authors reported the residual gas analysis (RGA) of the internal atmosphere inside micropackages with or/and without a getter film..$^{(12,22,31,49,58-61)}$ Such an analysis can be performed by punching the cap and measuring the released gas with a high-performance mass spectrometer. ${ }^{(12,58)}$ The main residual gases are most often $\mathrm{H}_{2}, \mathrm{~N}_{2}, \mathrm{CH}_{4}$ and other hydrocarbons, $\mathrm{CO}$ and $\mathrm{CO}_{2}$, and noble gases. Despite the potential large release of $\mathrm{H}_{2} \mathrm{O}$ during bonding, ${ }^{(12)}$ the partial pressures of $\mathrm{O}_{2}$ and $\mathrm{H}_{2} \mathrm{O}$ are typically low or not detected for bonded packages with prior outgassing. This might partly originate from re-adsorption on internal walls. Nevertheless, as shown below, a very low partial pressure of oxidizing gases can produce a significant oxidation of getter films. Argon is also observed when the getter film or other films are deposited by Ar sputtering. ${ }^{(31)}$ It was observed that the annealing of a sputtered getter film prior to bonding only partially minimizes argon release. ${ }^{(31)}$ Another solution is to use krypton $^{(53)}$ or xenon instead of argon as the sputtering gas for the getter film (and other films). Indeed, as well known, ${ }^{(62)}$ the noble gas content in sputtered films is reduced by using a heavier sputtering gas. To prevent noble gas release by getter films, evaporation instead of sputtering was used in our previous works for the deposition of various getter multilayers and alloys. ${ }^{(63-69)}$

In the ASTM 798-97 standard, ${ }^{(70)}$ the getter film sorption capacity is defined as the quantity of sorbed gas beyond which the gettering rate decreases to $5 \%$ of its value 3 min after the start of the test. Since the getter pumping rate requirement during the few hours of the outgassing, wafer bonding, and getter film thermal activation steps is expected to be $\geq 10^{3}$ higher than that after few days at room temperature, using this getter capacity definition is not very appropriate in the case of getter films for wafer-level packaging. Depending on outgassing conditions before bonding, the gas load during processing can be higher or lower than that during the package lifetime of $10-20$ years $\left(8.6 \times 10^{4}-1.7 \times 10^{5} \mathrm{~h}\right)$ at room temperature.

\section{Nonevaporable Getter Materials}

The NEG materials used in WLP processes are single reactive metals (mainly Zr, V, Ti, Hf, and $\mathrm{Nb}$ ) or alloys based on reactive metals eventually coated with a passivating or sacrificial layer. Some useful physicochemical data of the main reactive metals used in getter films are gathered in Table 2. 
Table 2

Some properties of reactive metals used in getter films. Data of columns 2-5, 6, and 7-8 are respectively from Refs. 71, 72 , and 73 except ${ }^{\mathrm{a}}$ from Ref. $74,{ }^{\mathrm{b}}$ from Ref. $75,{ }^{\mathrm{c}}$ from Ref. 76, and ${ }^{\mathrm{d}}$ from Ref. 77.

\begin{tabular}{|c|c|c|c|c|c|c|c|}
\hline Element & $\begin{array}{c}\text { Electro- } \\
\text { negativity }\end{array}$ & $\begin{array}{c}\text { Work } \\
\text { function } \\
(\mathrm{eV})\end{array}$ & $\begin{array}{l}\text { Oxide heat of } \\
\text { formation } \\
(\mathrm{kJ} / \text { mole })\end{array}$ & $\begin{array}{c}\text { Entropy } \\
\left(\mathrm{J} \cdot \mathrm{K}^{-1} \mathrm{~mol}^{-1}\right)\end{array}$ & $\begin{array}{l}\text { Oxygen heat of } \\
\text { dissolution in } \\
\text { pure metal } \\
(\mathrm{kJ} / \mathrm{mol})\end{array}$ & $\begin{array}{c}\text { Oxygen } \\
\text { diffusion length } \\
\text { at } 250^{\circ} \mathrm{C}-2 \mathrm{~h} \\
(\mathrm{~nm})\end{array}$ & $\begin{array}{c}\text { Oxygen } \\
\text { solubility at } \\
250^{\circ} \mathrm{C} \\
(\%)\end{array}$ \\
\hline $\mathrm{Ba}$ & 0.89 & 2.35 & $\begin{array}{c}\mathrm{BaO}:-548 \\
\mathrm{BaO}_{2}:-643.3\end{array}$ & $\begin{array}{c}\text { Ba: } 62.48 \\
\mathrm{BaO}: 72.7 \\
\mathrm{BaO}_{2}: \text { N.A. }\end{array}$ & & & \\
\hline $\mathrm{Y}$ & 1.22 & 3.1 & $\mathrm{Y}_{2} \mathrm{O}_{3}:-1905.31$ & $\begin{array}{c}\mathrm{Y}: 44.4 \\
\mathrm{Y}_{2} 0_{3}: 99.08\end{array}$ & & 3300 & 0.33 \\
\hline $\mathrm{Ti}$ & 1.54 & 4.3 & $\begin{array}{c}\mathrm{TiO}:-519.7 \\
\mathrm{TiO}_{2}:-966 \\
\mathrm{Ti}_{2} \mathrm{O}_{3}:-1520.9 \\
\mathrm{Ti}_{3} \mathrm{O}_{5}:-2459.4\end{array}$ & $\begin{array}{c}\mathrm{Ti}: 30.72 \\
\mathrm{TiO}: 50 \\
\mathrm{TiO}_{2}: 50.62 \\
\mathrm{Ti}_{2} \mathrm{O}_{3}: 78.8 \\
\mathrm{TiO}_{5}: 129.3\end{array}$ & -560.66 & $<0.1$ & 33 \\
\hline $\mathrm{Zr}$ & 1.33 & 4.05 & $\mathrm{ZrO}_{2}:-1100.6$ & $\begin{array}{c}\mathrm{Zr}: 39.0 \\
\mathrm{ZrO}_{2}: 50.36\end{array}$ & -619.23 & 0.14 & 29 \\
\hline Hf & 1.3 & 3.9 & $\mathrm{HfO}_{2}:-1144.7$ & $\begin{array}{c}\mathrm{Hf}: 43.56 \\
\mathrm{HfO}_{2}: 59.3\end{array}$ & -552.29 & 0.016 & 17 \\
\hline $\mathrm{V}$ & 1.63 & 4.3 & $\begin{array}{c}\mathrm{VO}:-431.8 \\
\mathrm{VO}_{2}:-716.6 \\
\mathrm{~V}_{2} \mathrm{O}_{3}:-1218.8 \\
\mathrm{~V}_{2} \mathrm{O}_{4}:-1427 \\
\mathrm{~V}_{2} \mathrm{O}_{5}:-1550 \\
\mathrm{~V}_{3} \mathrm{O}_{5}:-1933\end{array}$ & $\begin{array}{c}\mathrm{V}: 28.94 \\
\mathrm{VO}: 39 \\
\mathrm{VO}_{2}: 61.5 \\
\mathrm{~V}_{2} \mathrm{O}_{3}: 98.3 \\
\mathrm{~V}_{2} \mathrm{O}_{4}: 103 \\
\mathrm{~V}_{2} \mathrm{O}_{5}: 130 \\
\mathrm{~V}_{3} \mathrm{O}_{5}: 163\end{array}$ & -422.46 & 66 & 3.5 \\
\hline $\mathrm{Nb}$ & 1.6 & 4.3 & $\begin{array}{c}\mathrm{NbO}:-405,8 \\
\mathrm{NbO}_{2}:-796.2 \\
\mathrm{Nb}_{2} \mathrm{O}_{5}:-1899.5\end{array}$ & $\begin{array}{c}\mathrm{vNb}: 36.4 \\
\mathrm{NbO}: 48.1 \\
\mathrm{NbO}_{2}: 64.5 \\
\mathrm{Nb}_{2} \mathrm{O}_{5}: 137.3\end{array}$ & -386.18 & 370 & 0.33 \\
\hline $\mathrm{Fe}$ & 1.83 & 4.5 & $\begin{array}{c}\mathrm{FeO}:-272 \\
\mathrm{Fe}_{2} \mathrm{O}_{3}:-824.2 \\
\mathrm{Fe}_{3} \mathrm{O}_{4}:-118.4\end{array}$ & $\begin{array}{c}\text { Feo: } 50.75 \\
\mathrm{Fe}_{2} \mathrm{O}_{3}: 87.4 \\
\mathrm{Fe}_{3} \mathrm{O}_{4}: 145.27\end{array}$ & $\begin{array}{c}-155.6(\mathrm{Fe} \alpha) \\
-174.39(\mathrm{Fe} \gamma) \\
-155.6(\mathrm{Fe} \delta)\end{array}$ & $<0.1^{\mathrm{a}}$ & $<0.1^{\mathrm{b}}$ \\
\hline Co & 1.88 & 5.0 & $\begin{array}{l}\mathrm{CoO}:-137.7 \\
\mathrm{Co}_{3} \mathrm{O}_{4}:-891\end{array}$ & $\begin{array}{c}\mathrm{Co}: 30.0 \\
\mathrm{CoO}: 53 \\
\mathrm{Co}_{3} \mathrm{O}_{4}: 102.5\end{array}$ & -72.42 & $<0.1^{\mathrm{c}}$ & $<0.1^{\mathrm{d}}$ \\
\hline $\mathrm{La}$ & 1.1 & 3.0 & $\mathrm{La}_{2} \mathrm{O}_{3}:-1793.7$ & $\begin{array}{c}\mathrm{La}: 56.9 \\
\mathrm{La}_{2} \mathrm{O}_{3}: 127.32\end{array}$ & & - & $0.3^{\mathrm{d}}$ \\
\hline
\end{tabular}

NEG films are initially inactive and have to be activated to enable the sorption of surrounding gases. This is achieved by removing the passivating surface layer by thermal annealing in vacuum, in order to obtain a fresh and reactive metallic surface. In WLP processes, the getter material should ideally be activated during wafer/die bonding, ${ }^{(29)}$ but the thermal activation step is also commonly performed before cap sealing. ${ }^{(37,68)}$ A reactivation of the getter after bonding can also be implemented to increase the getter sorption lifetime. Thermal activation with a low thermal budget is a desirable characteristic for a getter film. For ultrahigh vacuum applications, a low activation temperature $\left(<300{ }^{\circ} \mathrm{C}\right)$ is sought to allow a wider range of materials and tolerate a long activation time. Instead, in WLP processes, both 
the activation time and the temperature must be limited to reduce the processing time and cost, and to be compatible with encapsulated devices. This is the reason why the values extrapolated at $250{ }^{\circ} \mathrm{C}$ were chosen for the oxygen diffusion length and solubility given in Table 2 .

In most published works, cathode sputtering is used as the deposition technique. Deposition conditions leading to a columnar structure with a high density of grain boundaries, and to a high surface roughness, are widely used. This increases the specific area for gas adsorption and promotes diffusion processes during getter activation and gas sorption. To obtain high activation and sorption performance, a getter material should also be highly reactive, should have large diffusion lengths and solubilities for lights atoms, and should be able to decompose hydrocarbons and form stable hydrides. As these conditions are difficult to fulfill with a single film, alloy films or multilayers are commonly used.

Many binary, ternary, and even quaternary alloys have been studied as getter films in the literature. Among them, zirconium-based alloys, notably $\mathrm{Zr}_{x} \mathrm{~V}_{y}, \mathrm{Zr}_{x} \mathrm{Ti}_{y}, \mathrm{Zr}_{x} \mathrm{Ti}_{y} \mathrm{~V}_{z}, \mathrm{Zr}_{x} \mathrm{~V}_{x} \mathrm{Fe}_{y}$, and $\mathrm{Zr}_{x} \mathrm{Co}_{y} \mathrm{RE}_{z}$, where $\mathrm{RE}$ is a mixture of rare-earth metals ( $\mathrm{La}, \mathrm{Ce}$, and $\mathrm{Nd}$ ), are the most widely examined and applied. ${ }^{(38,54,56,57,60,78-81)}$ For example, $\mathrm{Zr}_{x} \mathrm{Ti}_{y} \mathrm{~V}_{z}$ is the getter film used in many accelerators worldwide to improve the vacuum level.

The use of multilayers is another way to improve getter film characteristics. Getter multilayers are typically single or alloyed getter films with a top passivating or sacrificial layer deposited in situ, or/and with a sublayer. Table 3 provides a non-exhaustive survey of the main single films and getter multilayers investigated previously with some of their characteristics. The motivation for the use of a sublayer and/or a top layer on a getter film is briefly summarized below.

$\mathrm{Ni}, \mathrm{Cr}, \mathrm{Pt}$, and Ru were used as sublayers for Ti getter films, mainly to modify the Ti film structure in order to obtain a columnar structure with small grains that, as mentioned above, is known to highly promote the activation and sorption characteristics. $\mathrm{Cr}$ can also reduce the native oxide on $\mathrm{Si}$. $\mathrm{Au}, \mathrm{Pt}, \mathrm{Pd}, \mathrm{Pd}-\mathrm{Ag}, \mathrm{Cu}, \mathrm{Ni}, \mathrm{Al}$, and $\mathrm{Mg}$ were used as top layers. $\mathrm{Au}$, $\mathrm{Pt}$, and $\mathrm{Pd}$ do not react with oxygen and are thus efficient passivation layers. $\mathrm{Pd}, \mathrm{Pd}-\mathrm{Ag}$, and $\mathrm{Ni}$ are hydrogen catalyzers and were used to increase hydrogen intake while passivating the getter films and limiting poisonous effects on hydrogen sorption. $\mathrm{Cu}$ and $\mathrm{Ni}$ were selected as sacrificial layers on Ti likely because they are not easily oxidized when compared with getter materials, but the activation mechanism was not investigated and remains unclear. $\mathrm{Mg}$ and $\mathrm{Al}$ are materials with low melting points of 650 and $660{ }^{\circ} \mathrm{C}$, respectively. They were coated on Ba getter films to form alloy getters with high performance characteristics. ${ }^{(94)}$ All these works showed that the activation temperature of single getter films can be reduced, and/or their sorption performance characteristics can be improved, by adding a suitable top or sublayer.

The phenomena involved in thermal activation and gas sorption depend on temperature, the materials used, and the gaseous environment. In the following, we will examine the two cases of uncoated NEG films passivated by native oxide after air exposure and of NEG materials coated in situ with a thin passivating or sacrificial layer. 
Table 3

Survey of getter single films and multilayers previously investigated for vacuum packaging.

\begin{tabular}{|c|c|c|c|c|c|}
\hline Getter & Thickness (nm) & $\begin{array}{l}\text { Deposition } \\
\text { method }\end{array}$ & Activation and/or sorption & Experimental method & Ref. \\
\hline \multicolumn{6}{|l|}{ Single layer } \\
\hline Ti & 450 & Evaporation & Sorption detected after $400{ }^{\circ} \mathrm{C}-1 \mathrm{~h}$ & $\begin{array}{l}\text { Glass ampoule sealing } \\
\text { technique }\end{array}$ & 82 \\
\hline $\mathrm{Ti}$ & 2000 & Sputtering & Sorption detected after $200^{\circ} \mathrm{C}-4 \mathrm{~min}$ & MEMS integration & 29 \\
\hline $\mathrm{Ti}$ & 1000 & Evaporation & $\begin{array}{l}\text { Residual pressure of } 0.5 \mathrm{mbar} \text { in a package } \\
\text { sealed at } 400^{\circ} \mathrm{C}-1 \mathrm{~h} 30 \mathrm{~min}\end{array}$ & MEMS integration & 31 \\
\hline $\mathrm{Ti}$ & 600 & Evaporation & $\begin{array}{c}\text { Sorption capacity of } 10^{-6} \mathrm{mbar} \cdot \mathrm{L} / \mathrm{cm}^{2} \\
\text { after } 300^{\circ} \mathrm{C}-1 \mathrm{~h}\end{array}$ & Vacuum annealing & 83 \\
\hline $\mathrm{Zr}$ & $?$ & Sputtering & $\begin{array}{c}\text { Partial activation and some pumping can be } \\
\text { observed after heating to } \\
140^{\circ} \mathrm{C}-24 \mathrm{~h}\end{array}$ & Vacuum annealing & 84 \\
\hline $\mathrm{Zr}$ & 50000 & Foil & $\begin{array}{l}\text { Activation energy for oxygen diffusion of } \\
\qquad 50.4 \mathrm{~kJ} / \mathrm{mol}\end{array}$ & Vacuum annealing & 85 \\
\hline $\mathrm{Zr}$ & 200 & Evaporation & $\begin{array}{c}\text { Sorption capacity of } 2 \times 10^{-7} \mathrm{~mol} / \mathrm{cm}^{2} \\
\text { after } 300{ }^{\circ} \mathrm{C}-1 \mathrm{~h}\end{array}$ & Vacuum annealing & 86 \\
\hline V & 200 & Evaporation & $\begin{array}{c}\text { Sorption capacity of } 2 \times 10^{-7} \mathrm{~mol} / \mathrm{cm}^{2} \\
\text { after } 300{ }^{\circ} \mathrm{C}-1 \mathrm{~h}\end{array}$ & Vacuum annealing & 86 \\
\hline Y & 200 & Evaporation & $\begin{array}{l}\text { Sorption capacity of } 10^{-6} \mathrm{~mol} / \mathrm{cm}^{2} \\
\text { after } 300^{\circ} \mathrm{C}-1 \mathrm{~h}\end{array}$ & Vacuum annealing & 88 \\
\hline \multicolumn{6}{|l|}{ Sublayer } \\
\hline $\mathrm{Ti} / \mathrm{Cr}$ & $450 / 60$ & Evaporation & Sorption detected after $325^{\circ} \mathrm{C}-1 \mathrm{~h}$ & $\begin{array}{l}\text { Glass ampoule sealing } \\
\text { technique }\end{array}$ & 82 \\
\hline $\mathrm{Ti} / \mathrm{Pt}$ & $450 / 60$ & Evaporation & Sorption detected after $350^{\circ} \mathrm{C}-1 \mathrm{~h}$ & $\begin{array}{l}\text { Glass ampoule sealing } \\
\text { technique }\end{array}$ & 82 \\
\hline $\mathrm{Ti} / \mathrm{Ru}$ & $300 / 60$ & Evaporation & $\begin{array}{l}\text { Lower activation rate than without Ru. } \mathrm{N}_{2} \\
\text { sorption capacity }=10^{-5} \mathrm{mbar} \cdot \mathrm{L} / \mathrm{cm}^{2} \\
\text { after } 300^{\circ} \mathrm{C}-1 \mathrm{~h}\end{array}$ & Vacuum annealing & 83 \\
\hline $\mathrm{Zr} / \mathrm{Ti} / \mathrm{Ru}$ & & Evaporation & $\begin{array}{l}\text { Initial } \mathrm{N}_{2} \text { sorption rate } 10^{-1} \mathrm{~L} \cdot \mathrm{s}^{-1} \mathrm{~cm}^{-2} . \text { Best } \\
\mathrm{N}_{2} \text { sorption capacity }\left(3 \times 10^{-5} \mathrm{mbar} \cdot \mathrm{L} / \mathrm{cm}^{2}\right) \\
\text { after } 250^{\circ} \mathrm{C}-1 \mathrm{~h} \text { activation }\end{array}$ & Vacuum annealng & 83 \\
\hline \multicolumn{6}{|l|}{ Top layer } \\
\hline $\mathrm{Au} / \mathrm{Ti}$ & $5 / 100$ & Evaporation & $\begin{array}{l}\text { Sorption capacity of } 10^{-8} \mathrm{~mol} / \mathrm{cm}^{2} \\
\text { after } 300^{\circ} \mathrm{C}-1 \text { h activation }\end{array}$ & Vacuum annealing & 63 \\
\hline $\mathrm{Au} / \mathrm{Ti}$ & $30 / 1000$ & Evaporation & $\begin{array}{l}\text { Residual pressure of } 0.07 \mathrm{mbar} \text { in a package } \\
\text { sealed at } 400^{\circ} \mathrm{C}-1 \mathrm{~h} 30 \mathrm{~min}\end{array}$ & MEMS integration & 31 \\
\hline $\mathrm{Pd} / \mathrm{Ti}$ & $50 / 1300$ & Evaporation & $\begin{array}{l}\text { Sorption rate of } 0.028 \mathrm{l} / \mathrm{s} \text { measured } \\
\text { after } 133^{\circ} \mathrm{C}-12 \mathrm{~h} \text { activation }\end{array}$ & Vacuum annealing & 89 \\
\hline $\mathrm{Ni} / \mathrm{Ti}$ & $30 / 1000$ & Evaporation & $\begin{array}{l}\text { Residual pressure of } 0.04 \mathrm{mbar} \text { in a package } \\
\text { sealed at } 400{ }^{\circ} \mathrm{C}-1 \mathrm{~h} 30 \mathrm{~min}\end{array}$ & MEMS integration & 28 \\
\hline $\mathrm{Au} / \mathrm{Zr}$ & $20 / 100$ & Evaporation & $\begin{array}{l}\text { Sorption capacity of } 2 \times 10^{-6} \mathrm{~mol} / \mathrm{cm}^{2} \\
\text { after } 300^{\circ} \mathrm{C}-1 \text { h activation }\end{array}$ & Vacuum annealing & 65 \\
\hline $\mathrm{Au} / \mathrm{V}$ & $5 / 100$ & Evaporation & & Vacuum annealing & 65 \\
\hline $\mathrm{V} / \mathrm{Zr}$ & $20 / 100$ & Evaporation & $\begin{array}{l}\text { Sorption capacity of } 4 \times 10^{-7} \mathrm{~mol} / \mathrm{cm}^{2} \\
\text { after } 300^{\circ} \mathrm{C}-1 \text { h activation }\end{array}$ & Vacuum annealing & 68 \\
\hline $\mathrm{Nb} / \mathrm{Ti}$ & $1500 / 1000000$ & Evaporation & $\begin{array}{l}\text { Sorption detected at } 200^{\circ} \mathrm{C} \\
\text { during a ramp rate of } 14^{\circ} \mathrm{C} / \mathrm{s}\end{array}$ & Vacuum annealing & 90 \\
\hline $\begin{array}{l}\mathrm{Pd} / \mathrm{Ti}-\mathrm{Zr} \\
\text { and } \mathrm{Pd}-\mathrm{Ag} / \mathrm{Ti}-\mathrm{Zr}\end{array}$ & $? / 500$ & Sputtering & $\begin{array}{l}\text { High sticking coefficient for } \mathrm{H}_{2} \text { of } \mathrm{Pd} \text { and } \\
\text { large } \mathrm{H}_{2} \text { sorption capacity of Ti- } \mathrm{Zr} \text {. No } \\
\text { thermal activation required for } \mathrm{H}_{2} \text { sorption }\end{array}$ & Vacuum annealing & 91 \\
\hline $\mathrm{Pd} / \mathrm{Zr}-\mathrm{V}-\mathrm{Fe}$ & & $\begin{array}{l}\text { Electroplating /arc } \\
\text { melting }\end{array}$ & $\begin{array}{c}\text { In pure } \mathrm{H}_{2} \text {, Pd coating improves } \\
\text { hydrogenation rates of } \mathrm{Zr}-\mathrm{V}-\mathrm{Fe} \text { by } 31 \% \\
\text { without losing the maximum hydrogen } \\
\text { absorption capacity }\end{array}$ & Vacuum annealing & 92 \\
\hline $\begin{array}{l}\mathrm{Pd}-\mathrm{Ag} / \mathrm{Ti}-\mathrm{Zr}-\mathrm{V} \\
\text { or } \mathrm{Zr}-\mathrm{V}-\mathrm{Fe}\end{array}$ & & $\begin{array}{l}\text { Electroplating/arc } \\
\text { melting }\end{array}$ & $\begin{array}{l}\mathrm{Pd}-\mathrm{Ag} \text { makes Zr-based alloy activation } \\
\text { easier, accelerates hydrogenation kinetics, } \\
\text { and slightly decreases the hydrogen } \\
\text { sorption capacity }\end{array}$ & Vacuum annealing & 93 \\
\hline $\mathrm{Mg}$ or $\mathrm{Al} / \mathrm{Ba}$ & & Evaporation & $\begin{array}{c}\text { Low activation temperature }\left(150^{\circ} \mathrm{C}\right) \text { and } \\
\text { high sorption capacity }\end{array}$ & & 94 \\
\hline
\end{tabular}




\section{Thermal Activation and Sorption of Getter Films}

\subsection{General considerations}

The thermal activation of getter films proceeds by the in-depth diffusion of atoms of the surface layer. In polycrystalline NEG films at low temperatures $\left(<0.5 T_{m}\right.$, where $T_{m}$ is the melting point), thermal diffusion is expected to be largely dominated by diffusion along grain boundaries. According to Fick's laws of diffusion, the diffusion length varies exponentially with the temperature and square root of time.

$$
L \propto \sqrt{D t} \text { with } D=D_{0} \exp \left(-E_{a} / k T\right)
$$

Here, $L$ is the diffusion length, $t$ the annealing time, $D$ the diffusivity, $D_{0}$ the diffusivity at infinite temperature, $E_{a}$ the thermal activation energy, $k$ the Boltzmann constant, and $T$ the absolute temperature.

The temperature dependence of the thermal activation step is thus determined by the activation energy of surface atom diffusion. However, the activation energy is not often measured in published works and, instead, an activation temperature is given. When surface analysis techniques are used to characterize the thermal activation, the initial activation temperature can be defined as the temperature beyond which the surface atom concentrations of the diffusing atoms are found to decrease. Likewise, the temperature of a full thermal activation can be defined as the temperature above which no further decrease in the concentration of diffusing surface atoms is observed. However, in a general way, comparisons of activation temperatures can be misleading if not clearly defined and not performed with the same analysis technique, annealing time, and ambient conditions.

Once activated, NEG films are able to pump gases, except noble gases, with good performance characteristics for $\mathrm{H}_{2} \mathrm{O}, \mathrm{O}_{2}, \mathrm{H}_{2}, \mathrm{CO}, \mathrm{CO}_{2}$, and possibly $\mathrm{N}_{2}$, and often with low or very low performance characteristics for hydrocarbons. Similarly to thermal activation, gas sorption can proceed by diffusion into the film bulk after the dissociation of molecules at the surface and sorption at surface sites. During outgassing, wafer bonding, and thermal activation steps, diffusion can be the limiting step, while at room temperature, the gas sorption process mainly depends on the initial pumping speed and surface coverage. ${ }^{(73)}$ The pumping speed per unit surface for a given gas $S_{g}$ is related to the impingement rate of molecules and the gas effective sticking coefficient.

$$
S_{g}=\frac{P}{\sqrt{2 \pi m T}} a
$$

Here, $P, m$, and $T$ are respectively the pressure, molecule mass, and temperature. The effective sticking coefficient $a$ takes into account all phenomena that enhance or inhibit atom trapping. At room temperature, the sticking coefficient is largely governed by the surface coverage, while at higher temperatures, diffusion and reactions must be taken into account. 
In the case of hydrogen, the sorption process is generally reversible because few metals form stable hydrides. Hydrogen is then in solid solution with an atomic concentration $x_{\mathrm{H}}$ at thermodynamical equilibrium and the pressure $P_{\mathrm{H}_{2}}$ given by Sieverts' law.

$$
x_{\mathrm{H}}=K \sqrt{P_{\mathrm{H}_{2}}}
$$

Here, $K$ is thermally activated.

Hydrogen molecules can then be partially released by a diffusion- or recombination-limited mechanism. This can be used to estimate the amount of sorbed hydrogen.

\subsection{Thermal activation of single and alloy getter films}

\subsubsection{Thermal activation of single and alloy getter films in UHV}

When exposed to air, single or alloy NEG films become passivated with a layer mainly containing oxides or hydroxides as well as a small amount of carbon due to contamination. In UHV, the removal of this superficial layer by thermal annealing mainly relies on the diffusion of surface species in the film bulk and on the outgassing of hydrogen and possibly of remaining water vapor. The thermal desorption of the oxide(s) can be safely neglected. In the case of a single element material, if the total Gibbs free energy is reduced, the diffusion of surface atoms in the film bulk is expected to occur until the solubility limit is reached. This occurs when the Gibbs free energy for oxide formation per mole is larger (less negative) than that of solid solution per oxygen mole. ${ }^{(73)}$ This is true for the reactive metals used in NEG films at any temperature or at sufficiently high temperatures. Then, the activation kinetics is driven by diffusion.

As detailed in Sect. 5, the thermal activation of single and alloy getter films is most often characterized in ultrahigh vacuum by surface analysis techniques. The getter film activation is then detected from the decrease in oxygen surface concentration and the increase in the concentration of getter film atoms in metallic state. This is illustrated in Fig. 2 for a co-evaporated $\mathrm{Zr}_{48} \mathrm{Co}_{52}$ film before and after in situ UHV annealing for $1 \mathrm{~h}$ at different temperatures.

It clearly shows the decrease in oxygen surface concentration and the increase in the surface concentration of cobalt and zirconium atoms in metallic state for annealing temperatures above $300{ }^{\circ} \mathrm{C}$. A detailed analysis showed that the native oxide after air exposure is mainly a mixture of $\mathrm{ZrO}_{2}, \mathrm{CoO}$, and $\mathrm{CoO}_{2}$ oxides and that, at $T \geq 400{ }^{\circ} \mathrm{C}$, no more cobalt oxide is found, while some $\mathrm{ZrO}_{2}$ is still present. This is consistent with the thermodynamics data shown in Table 2 and is typical of getter alloys with a superficial oxide composed of a mixture of oxides with different thermal stabilities. A similar analysis could be performed for carbides, nitrides, and hydrides.

A full and detailed in situ XPS analysis of the kinetics of activation and gas sorption kinetics of a sputtered $\mathrm{Zr}_{80} \mathrm{Co}_{15} \mathrm{RE}_{5}$ film where $\mathrm{RE}$ is a mixture of rare-earth metals (Ce, $\mathrm{La}$, and $\mathrm{Nd}$ ) 


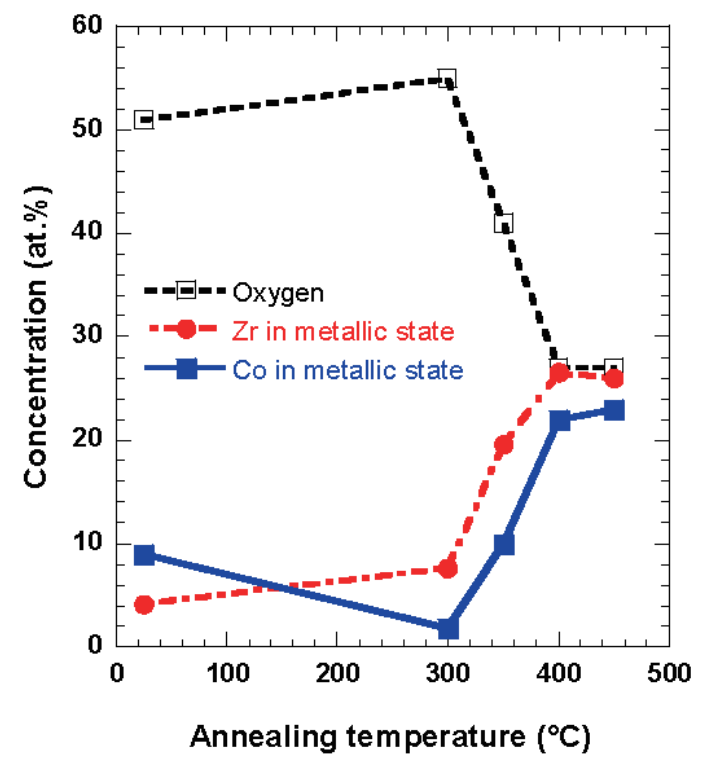

Fig. 2. (Color online) XPS measurements of surface concentrations of oxygen, cobalt in metallic state, and zirconium in metallic state of a co-evaporated $\mathrm{Zr}_{48} \mathrm{Co}_{52}$ film as functions of UHV annealing temperature. Annealing time: $1 \mathrm{~h}$. Pressure during annealing: $\sim 1 \times 10^{-9}$ mbar. Metallic Co and $\mathrm{Zr}$ atomic concentrations detected at room temperature originate from the $\mathrm{ZrCo}$ film below the native oxide.

was reported in Ref. 80. The authors found a reduction in the intensity of the O1s peak (mainly bonded to $\mathrm{Zr}$ ) and an increase in the intensity of the $\mathrm{Zr3d}$ peak as a function of annealing temperature [Fig. 3(a)]. ${ }^{(80)}$ The results shown in Fig. 2 are in agreement with this study. However, in Ref. 80, the onset of activation was found at $\sim 200^{\circ} \mathrm{C}$ [Fig. 3(a)] instead of about 300 ${ }^{\circ} \mathrm{C}$ for the co-evaporated $\mathrm{Zr}_{48} \mathrm{Co}_{52}$ film (Fig. 2). The full activation temperatures are about 350 and $400{ }^{\circ} \mathrm{C}$, respectively [see Figs. 2 and 3(a)]. This demonstrates the need to clearly define the activation temperature used in getter film investigations. The lower initial and full activation temperatures of the $\mathrm{Zr}_{80} \mathrm{Co}_{15} \mathrm{RE}_{5}$ film can be attributed both to its larger $\mathrm{Zr}$ content, to the rareearth doping that is often added for this purpose, ${ }^{(95)}$ and possibly to its different structure. The corresponding activation energy for oxygen diffusion from the surface to the bulk, estimated from an Arrhenius plot, was found to be $0.21 \mathrm{eV}^{(80)}$ Such a low value is expected for a diffusion occurring mainly along grain boundaries. Finally, Fig. 3(a) shows an increase in $\mathrm{C}_{1 \mathrm{~s}}$ concentration above $200{ }^{\circ} \mathrm{C}$, which is attributed to hydrocarbon decomposition at the surface. $\left({ }^{(80)}\right.$ This decomposition is likely promoted by the catalytic effect of the cobalt content in this alloy. ${ }^{(96)}$ The authors also reported in Ref. 80 in situ measurements of the kinetics of the activation process of this film. Such measurements are largely missing in published works. The measured decrease in superficial oxide thickness during activation [Fig. 3(b)] and other data in Ref. 80 show that the $\mathrm{Zr}_{80} \mathrm{Co}_{15} \mathrm{RE}_{5}$ film activation is initially fast, then followed by a slower regime attributed to the formation of a diffusion barrier near the surface. 


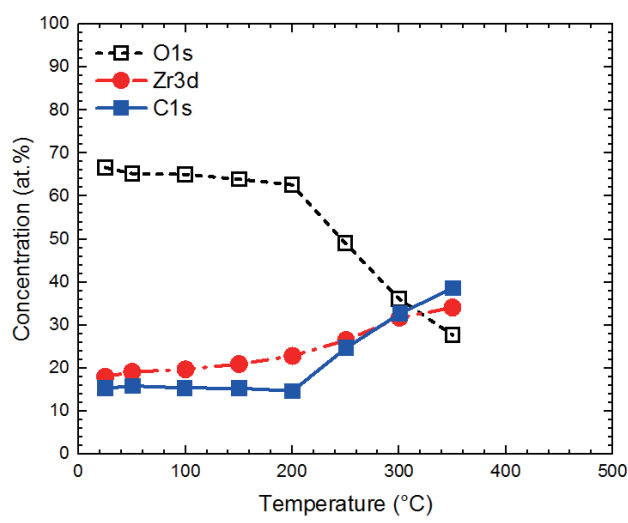

(a)

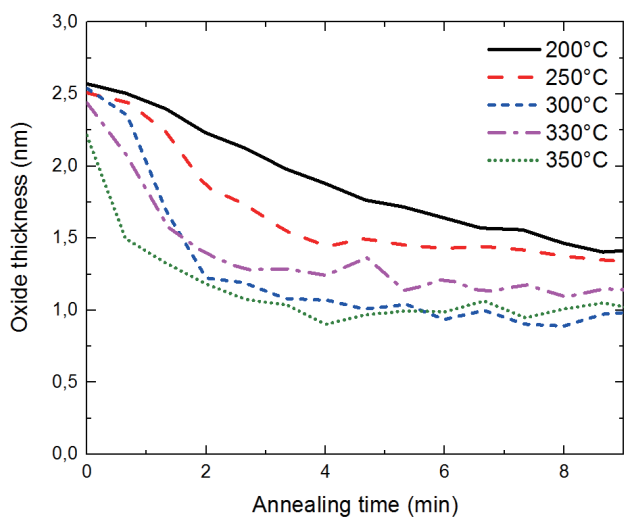

(b)

Fig. 3. (Color on line) (a) Atomic concentration as evaluated by XPS measurement of C 1s, O 1s, and Zr 3d orbitals as a function of temperature $( \pm 1 \%)$. (b) Oxide thickness variations as functions of UHV annealing time at different temperatures. Results for a sputtered $\mathrm{Zr}_{80} \mathrm{Co}_{15} \mathrm{Re}_{5}$ film. Adapted with permission from Ref. 80. Copyright 2019 from American Chemical Society.

\subsubsection{Thermal activation and sorption of single and alloy getter films in secondary or primary vacuum}

In UHV, gas sorption during activation is negligible or low, and the sorption process can be separately analyzed by surface analysis techniques and gas sorption kinetics measurements. A higher background pressure may have a significant effect on the thermal activation and sorption of getter films. This can be inferred from in situ XPS or/and ellipsometry experiments of pure $\mathrm{Zr}$ and Ti films exposed to very low partial pressures of oxygen. ${ }^{(97,98)}$ These experiments showed that, even for an oxygen pressure as low as $2-3 \times 10^{-8}$ mbar, a fast oxidation occurs at temperatures below the activation temperature of getter films (Fig. 4). At higher temperatures, the oxidation and dissolution rates can become similar and, as demonstrated for $\mathrm{Zr}$, this stops oxide growth. ${ }^{(97)}$ Thus, the surface oxidation of a getter film very likely occurs in wafer-level packages during the outgassing, bonding, and thermal activation of getter films. Consequently, activation, gas sorption, and oxidation are not clearly separated and the onset of decrease or saturation of surface concentrations of oxygen and other species can no longer be simply used to define activation temperatures. Instead, the beginning of gas pumping, or better the activation energy of total oxygen intake, should be used whatever the mechanisms involved. A similar issue could also be examined for nitriding and carbonizing gases, but their effects should be lower than those of oxidizing gases.

\subsection{Thermal activation of getter multilayers}

\subsubsection{Thermal activation of getter multilayers in UHV}

The thermal activation of multilayer getter films can proceed either by the solid-state outdiffusion of the getter films through the top layer, the in-diffusion of the top layer, both of them, or the dewetting of the top layer (Fig. 5). 


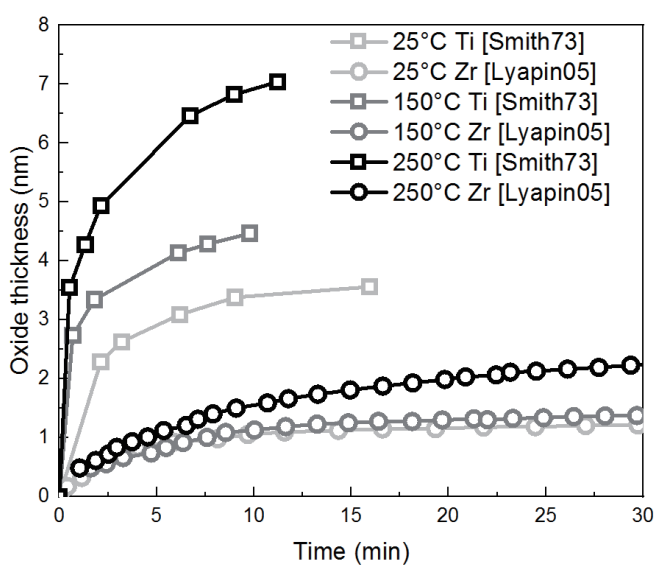

Fig. 4. Oxidation kinetics of pure $\mathrm{Zr}$ and Ti films at $2-3 \times 10^{-8}$ mbar oxygen pressure. Data extracted from Refs. 97 and 98.

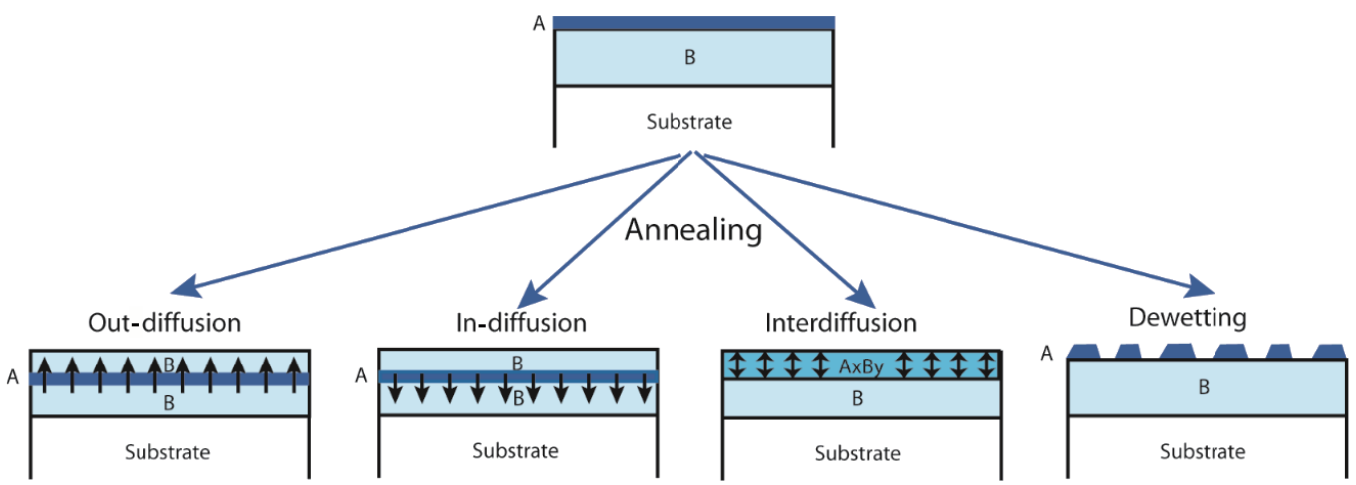

Fig. 5. (Color online) Principle of activation of a AB multilayer getter film by out-diffusion of the getter film, indiffusion of the top layer, interdiffusion of top layer and getter film and alloy formation, and dewetting of the top layer.

Getter activations by out-diffusion and dewetting are respectively illustrated in Figs. 6(a) and Fig. 6(b) by SEM cross sections after the thermal annealing and air exposure of an evaporated $\mathrm{Au} / \mathrm{Ti}$ multilayer ${ }^{(63,65)}$ and of an evaporated $\mathrm{Au} / \mathrm{Zr}$ film. ${ }^{(65)}$

Solid-state dewetting is a less common case and will be first briefly discussed. The dewetting of very thin films occurs at temperatures below the melting temperature when the total energy of surfaces and interfaces is reduced by the nucleation and growth of voids. It depends on many factors including film thickness, temperature, deposition technique, film stress, grain size, grain growth, and grain boundary energy. ${ }^{(99,100)}$ It is considered to be driven either by the surface diffusion ${ }^{(99)}$ or self-diffusion of the film at the interface. ${ }^{(100)}$

When no dewetting occurs, the activation process is driven by the out-diffusion, in-diffusion or interdiffusion of the top layer and getter film. At high temperatures, solid-state diffusion in metals can occur in the lattice, in the extended defects, and along grain boundaries ${ }^{(101)}$ 


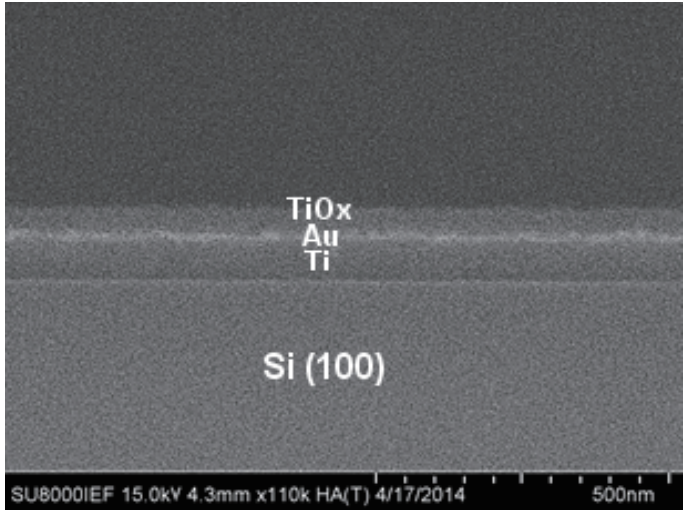

(a)
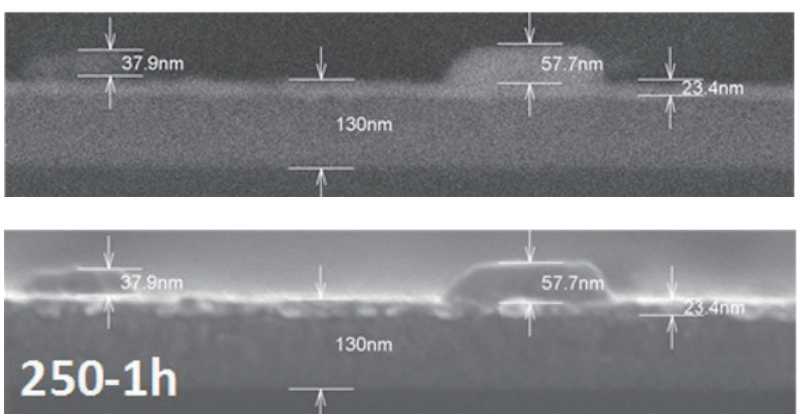

(b)

Fig. 6. SEM cross sections after air exposure of (a) a $\mathrm{Au}(5 \mathrm{~nm}) / \operatorname{Ti}(100 \mathrm{~nm})$ multilayer annealed at $350{ }^{\circ} \mathrm{C}$ for $16 \mathrm{~h}$ (backscattered electron imaging mode) and (b) a $\mathrm{Au}(20 \mathrm{~nm}) / \operatorname{Zr}(100 \mathrm{~nm})$ multilayer annealed at $250{ }^{\circ} \mathrm{C}$ for 1 $\mathrm{h}$ showing $\mathrm{Au}$ dewetting with formation of $\mathrm{Au}$ islands on the surface (top: backscattered electron image; bottom: secondary electron image).

with eventually the migration of grain boundaries, ${ }^{(102)}$ but it is largely admitted that, for low-activation-temperature getter films, diffusion is mainly governed by that along grain boundaries. In UHV, diffusion is expected to vanish when the atom concentrations of the getter film at the top and bottom interfaces of the coating become similar.

\subsubsection{Thermal activation of getter multilayers in primary and secondary vacuum}

For the reasons discussed below, as for getters passivated by natural oxide, the activation and sorption processes of getter multilayers are expected to be very different under UHV conditions and at pressures found in wafer-level packages.

The thermal activation of a getter multilayer by top layer dewetting can be changed by the gaseous environment because, according to Kosinova et al., ${ }^{(100)}$ dewetting can depend on annealing atmosphere through changes in the surface anisotropy of materials.

In the more common case of thermal activation driven by diffusion, at pressures found in wafer-level packages, the getter atoms out-diffused through the capping layer are rapidly oxidized, and carbides or nitrides might also form. This may provide a sink for further outdiffusion of the getter atoms. Oxygen can also eventually diffuse through the top layer and oxidize the interface and reduce diffusion. More generally, according to the surface potential model, ${ }^{(103)}$ the out-diffusion process can be enhanced if the top layer is more electronegative than the getter film, and its work function is decreased by gas species adsorbed at the surface. This is the case for a $\mathrm{Au} / \mathrm{Ti}$ multilayer exposed to oxygen. The out-diffusion process can also be enhanced if the top layer is less electronegative than the getter film, and its work function is decreased by adsorbed species. This is the case of $\mathrm{Pd} / \mathrm{Ti}$ exposed to oxygen. In the two other cases, the rate of out-diffusion is reduced. An example is Au/Ti exposed to hydrogen or CO. 
This model can also be applied in the case of the in-diffusion of the top layer by reversing the role of the materials. In the presence of a gas mixture or interdiffusion, surface potential effects are competing and more difficult to predict. ${ }^{(103)}$ These experiments reviewed in Ref. 103 were mainly performed at high temperatures and their validity at moderate temperatures should be examined. Nevertheless, they show that, similarly to uncoated getters, the activation and sorption of multilayer getters can be largely modified by a gaseous environment.

\section{Characterization Requirements for Getter Films Used in WLP}

Because of the small thickness of the passivating oxide layer (a few nm), the activation of NEG materials was very often characterized in UHV by surface characterization techniques. For example, X-ray photoelectron spectroscopy (XPS), ${ }^{(55,61,65,78-80,104)}$ which allows for the quantification and identification of bonds, and less commonly used Auger electron spectroscopy $(\mathrm{AES})^{(81)}$ have been used. Both techniques were eventually combined with ion beam etching for depth profiling. These techniques have analyzing depths in the 5-7 nm and $0.5-2.5 \mathrm{~nm}$ ranges, respectively. Secondary ion mass spectrometry was also used, ${ }^{(105)}$ notably to investigate the case of hydrogen, as well as UHV elastic recoil detection analysis (ERDA) for oxygen depth profiling. ${ }^{(54)}$ Although some artefacts due to electron-induced oxide reduction and oxygen sorption, ${ }^{(81)}$ carbon contamination, ion mixing during profiling, and the matrix effect can occur, these surface analysis techniques are well suited for a thorough analysis of the getter film activation process in ultrahigh vacuum. The activation process is then characterized by the variations in oxygen, carbon nitrogen, and metal peak intensities as functions of time and temperature.

The getter gas sorption is usually characterized by gas sorption kinetic measurements that provide, for a given gas, the initial gettering rate and getter capacity of the getter film. ${ }^{(53-57)} \quad$ Unfortunately such measurements require specific and rather sophisticated UHV equipment, ${ }^{(55,106,107)}$ which are not widely spread. They are typically performed at room temperature with $\mathrm{CO}$ and $\mathrm{H}_{2}$ gases as representatives of irreversibly and reversibly pumped gases respectively to comply with the ASTM standard, ${ }^{(70)}$ and sometimes with $\mathrm{N}_{2}, \mathrm{CO}_{2},{ }^{(55)}$ and hydrocarbon gases. ${ }^{(55)}$ Very few experiments were performed with gas mixtures. It was however demonstrated that poisoning effects can largely modify the sorption performance characteristics notably for hydrogen. ${ }^{(55,59,108)}$ The activation energy of getter films could also be characterized from the initial gas sorption rate at different temperatures, but sorption kinetics setups usually do not allow such experiments. For all these reasons, a multichamber UHV setup allowing the in situ characterization of the activated getter films and their sorption kinetics for various gases $\left(\mathrm{H}_{2}, \mathrm{CO}, \mathrm{O}_{2}, \mathrm{~N}_{2}\right.$, dry air, and $\left.\mathrm{CH}_{4}\right)$ at various temperatures is under construction in our laboratory.

As discussed above in Sects. 4.2.2 and 4.3.2, the gaseous environment can have a large effect on the thermal activation and gas sorption of getter films. Thus, for getter films intended for WLP, other procedures and/or characterization techniques must be considered. First, it is desirable to analyze the variations in both the surface and bulk compositions before, after, or better during annealing and under partial pressures of air or gases found in WLP. Ideally, 
such measurements should be nondestructive and performed in situ with a controlled gaseous atmosphere. Cross-sectional SEM and TEM measurements or surface analysis techniques with ion beam profiling allow in-depth composition analyses, but they generally cannot be performed in situ during annealing in primary vacuum and are destructive. A better option is the use of ion beam analysis techniques such as Rutherford backscattering or proton X-ray emission for heavy elements, and elastic recoil detection analysis or nuclear reaction analysis for light elements, ${ }^{(54,86,87,88)}$ although all these techniques require a particle accelerator.

A technique that enables the in situ characterization of single, alloy or multilayer getter films at pressures found in WLP is four-probe sheet resistance measurement. ${ }^{(69)}$ Its main advantages are, beside its simplicity, sensitivity, and rapidity, its ability to detect both surface layer and film bulk variations. A major counterpart is its indirect nature, i.e., the lack of chemical identification. Indeed, various physico-chemical phenomena can lead to a sheet resistance increase or decrease as a function of thickness and temperature. They can be the variations in the degree of electron scattering with thickness, grain size, densities of grain boundaries, defects or impurities, and the degree of surface or bulk oxidation, hydration, and so forth. ${ }^{(108-114)}$ In addition, transition metals have multiple possible oxidation states with highly variable electrical properties. Nevertheless, for a sufficiently thick film and a not very high temperature, electron scattering is no longer thickness-dependent, grain growth is weak, and surface and/or bulk oxidation can be detected as oxides have a much higher resistivity than pure metals and metallic alloys. This is illustrated in Fig. 7, which shows the time variations in the sheet resistances of evaporated $\mathrm{Ti}, \mathrm{Zr}$, and $\mathrm{V}$ metals during vacuum annealing at $250{ }^{\circ} \mathrm{C}$. These measurements were performed on films with their native oxide and for background pressures equal to $10^{-6}$ and $10^{-3}$ mbar, the latter one being generated by an air leak. In all cases, a sheet resistance increase was observed at a higher rate when the background pressure was higher. In the case of $Z_{x} \mathrm{~V}_{y}$ films, complementary analyses by Rutherford backscattering (RBS) showed that this can be attributed to oxygen intake by bulk diffusion and surface oxidation. ${ }^{(86)}$ Conversely, when annealing was performed under UHV $\left(<10^{-9}\right.$ mbar), RBS analyses showed that only the bulk diffusion

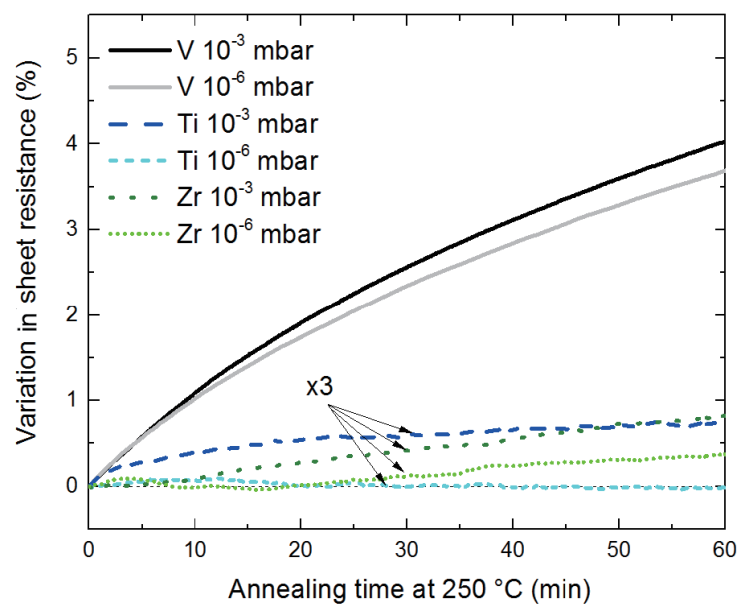

Fig. 7. (Color online) Relative variation in sheet resistance versus time at $250^{\circ} \mathrm{C}$ for $10^{-6}$ and $10^{-3}$ mbar. 
of oxygen from the native oxide is observed. ${ }^{(87)}$ As expected, the sheet resistance variation is much larger for $\mathrm{V}$ than for $\mathrm{Ti}$ and $\mathrm{Zr}$ because of the much larger oxygen diffusion length in this metal (see Table 2).

These experiments clearly show the effect of low partial pressures of oxidizing gases during getter film activation. The observed increase rate of sheet resistance with pressure can reflect either the decrease in underlying metallic film thickness due to surface oxidation or the increase in its resistivity due to bulk oxygen dissolution or both. These two phenomena are competing, are both dependent on temperature, and have similar time dependences. As discussed in Sect. 4.2.2 in the case of $\mathrm{Zr}$, oxygen dissolution is expected to dominate above a certain temperature.

Another interesting electrical property of metallic films is their temperature coefficient of resistance (TCR). The room-temperature TCR is related to the structural disorder in a film, and thus to the grain boundary density, which is a key factor for an activation at a low temperature. According to the empirical Mooij rule, ${ }^{(115)}$ the TCR becomes negative for metallic films with a resistivity higher than $150 \mu \Omega \cdot \mathrm{cm}$. Figure 8 shows the TCR values of various getter films as a function of resistivity (Mooij plot). It highlights separate groups for pure elements, $\mathrm{Zr}-\mathrm{Ti}, \mathrm{Zr}-$ $\mathrm{V}$, and $\mathrm{Zr}-\mathrm{Co}$ alloys. These groups exhibit low to high global disorders in their structures, with negative TCR films being amorphous. We found that the less activated getter films at $250{ }^{\circ} \mathrm{C}$ are the films with the highest structural order (pure films), as well as the films with the lowest structural order (amorphous films). ${ }^{(69)}$ This result confirms that the in-depth diffusion of surface species is promoted in a crystalline film with a high density of grain boundaries, i.e., a columnar structure with fine grains. Thus, for single and alloyed getter films, the TCR can be a good indicator of their oxygen gettering ability.

In conclusion, to take into account effects of the gaseous environment on getter films leading to oxidation, activation, and sorption, new experiments allowing the characterization of getter films in the pressure range found in wafer-level packages should be devised in the future.

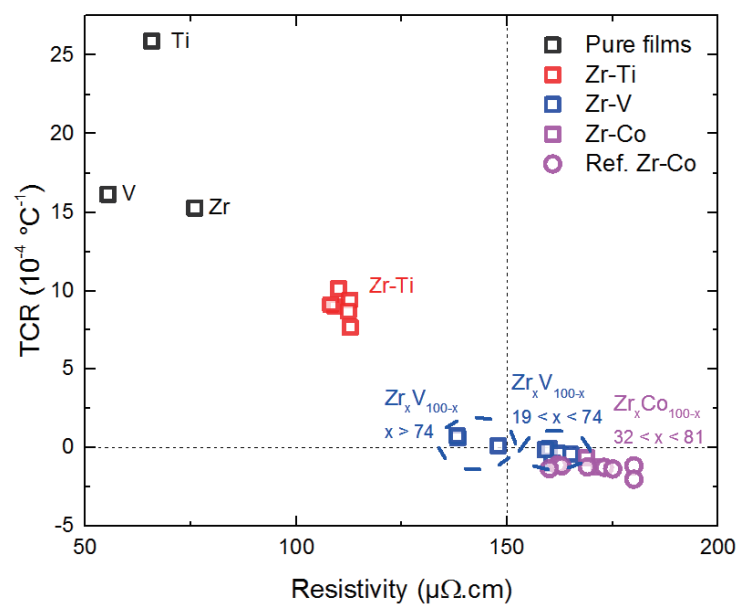

Fig. 8. (Color online) Mooij plot of some getter films. Squares: evaporated or co-evaporated 200-nm-thick films. Circles: $\mathrm{Zr}_{x} \mathrm{Co}_{100-x}$ films from Refs. 116-118. 


\section{Conclusion}

The analysis of gas generation sources inside a micropackage fabricated by wafer or chip bonding shows that outgassing during processing and reliability tests is the main cause of pressure rise inside a micropackage cavity. The gaseous environment and pressure inside the package cavity are clearly very far from UHV conditions and both the thermal activation and gas sorption of getter alloys and multilayers can be largely affected. For example, despite the low partial pressures of oxygen and water vapor found by RGA analyses in wafer-level packages, surface oxidation and/or oxygen sorption very likely occur during getter activation and all phenomena are competing. Poisonous effects are also expected to be highly significant. This has also important consequences on the characterization of getter films, which is often performed in ultrahigh vacuum. Thus, while theoretical investigations and measurements in UHV remain essential, new experiments allowing measurements under conditions similar to those found in wafer-level packages will have to be devised to obtain the reliable evaluation and prediction of getter film performance characteristic for wafer-level vacuum packaging.

\section{Acknowledgments}

Our experiments reported here were partly performed in the micro/nanotechnology facility of $\mathrm{C} 2 \mathrm{~N}$, which is part of the national network Renatech of French clean rooms centers. The authors wish to thank technicians and engineers of $\mathrm{C} 2 \mathrm{~N}$ for their assistance for film deposition and characterization. Part of this work was supported by Ph.D. grants of the French Ministry of Research and of the French National Agency of Research (ANR), and by several companies.

\section{References}

1 J. T. M. van Beek and R. Puers: J. Micromech. Microeng. 22 (2012) 013001. https://doi.org/10.1088/09601317/22/1/013001

2 V. Kempe: Inertial MEMS: Principles and Practice (Cambridge University Press, Cambridge, 2011). https:// doi.org/10.1017/CBO9780511933899

3 O. Brand, I. Dufour, S. Heinrich, and F. Josse: Resonant MEMS: Fundamentals, Implementation, and Application (Wiley, Weinheim, 2015). https://doi.org/10.1002/9783527676330

4 C. S. Lam, A. Gao, C.-M. Lin, and J. Zou: Proc. 7th Int. Symp. Acoustic Waves Devices Future Mobile Commun. Syst, (2018) 1. www.skyworksinc.com/downloads/press_room/published_articles/Intl_ Symposium_032018.pdf

5 H. M. Chu, R. T. Sasaki, and K. Hane: Microsyst. Technol. 24 (2018) 2159. https://doi.org/10.1007/s00542-017$3668-2$

6 T. P. Burg: Devices with Embedded Channels in Resonant MEMS: Fundamentals, Implementation and Applications (Wiley, Weinheim, 2015) p. 261. https://doi.org/10.1002/9783527676330.ch11

7 M. Poot and H. S. J. van der Zant: Phys. Rep. 511 (2012) 273. https://doi.org/10.1016/j.physrep.2011.12.004

8 T. Veijola: J. Micromech. Microeng. 24 (2004) 1109. https://doi.org/10.1088/0960-1317/14/7/034

9 H. Sumali: J. Micromech. Microeng. 17 (2007) 2231. https://doi.org/10.1088/0960-1317/17/11/009

10 W. Wang, J. Jia, and J. Li: J. Nanoeng. Nanosyst. 227 (2013) 162. https://doi.org/ 10.1177/1740349913486097

11 M. Belov, N. K. Quitoriano, S. Sharma, W. K. Hiebert, T. I. Kamins, and S. Evoy: J. Appl. Phys. 103 (2008) 074304. https://doi.org/10.1063/1.2891002

12 S. Tominetti and A. Della Porta: Conf. Reliability, Testing and Characterization of MEMS/MOEMS, Proc. SPIE 4558 (2001) 215. https://doi.org/10.1117/12.443004

13 M. Hasegawa, R. K. Chutani, R. Boudot, L. Mauri, C. Gorecki, X. Lin, and N. Passily: J. Micromech. Microeng. 23 (2013) 055022. https://doi.org/10.1088/0960-1317/23/5/055022 
14 H. Cao, C. H. Vermeer, S. Vanapalli, H. J. Holland, and H. J. Marcel ter Brake: J. Vac. Sci. Technol., A 33 (2015) 061601. https://doi.org/10.1116/1.4926961

15 F. Niklaus, C. Jansson, A. Decharat, J.-E. Källhammer, H. Pettersson, and G. Stemme: Conf. Infrared Technology and Applications XXXIII, Proc SPIE 6542 (2007) 65421M. https://doi.org/10.1117/12.719163

16 S. Tanaka, Y. Honjoya, and M. Esashi: Proc. 23rd IEEE Int. Conf. MicroElectroMechanicalSystems (MEMS 2010) 492-495. https://doi.org/ 10.1109/MEMSYS.2010.5442459

17 M. Esashi, S. Sugiyama, K. Ikeda, Y. Wang, and H. Miyashita: Proc. IEEE 86 (1998) 1628. https://doi.org/ $10.1109 / 5.704268$

18 S. J. Kwon, K. J. Hong, J. D. Lee, C. W. Oh, J. S. Yoo, and Y. B. Kwon: J. Vac. Sci. Technol., B 18 (2000) 1227. https://doi.org/10.1116/1.591366

19 D. Noda, M. Hatakeyama, K. Nishijyou, K. Sawada, and M. Ishida: Proc. IEEE 19th Int. Vacuum Nanoelectronics Conf. (IVNC 2006) 387. https://doi.org/ 10.1109/IVNC.2006.335230

20 H. Liu, K. Wei, Z. Li, W. Huang, Y. Xu, and W. Cui: Micromachines 9 (2018) 48. https://doi.org/10.3390/ mi9100481

21 S. H. Heo, H. J. Kim, J. M. Ha, and S. O. Cho: Nanoscale Res. Lett. 7 (2012) 258. https://doi.org/10.1186/1556276X-7-258

22 G. Longoni, A. Conte, and M. Moraja: Proc. IEEE Int. Reliability Physics Symposium (2006) 416. https://doi. org/ 10.1109/RELPHY.2006.251254

23 Z. Gan, D. Huang, W. Wang, D. Lin, and S. Kiu: Sens. Actuators, A 149 (2009) 159. https://doi.org/10.1016/ j.sna.2008.10.014

24 Y. Yang, E. J. Ng, Y. Chen, I. B. Flader and T. W. Kenny: J. Microelectromech. Syst. 25 (2016) 489. https://doi. org/10.1109/JMEMS.2016.2537829

25 R. R. Knight and R.G. Polcawich: Proc. IEEE Int. Symp. Inertial Sensors and Systems (INERTIAL) (2017) 105-108. https://doi.org/10.1109/ISISS.2017.7935658

26 S. Mack, H. Baumann, U. Gösele, H. Werner, and R. Schlögl: J. Electrochem. Soc. 144 (1997) 1106. http://doi. org/10.1149/1.1837540

27 J. Mitchell, G. R. Lahiji, and K. Najafi: Proc. Solid-State Sensors, Actuators, and Microsystems Workshop (2006) 376

28 S. Caplet, N. Sillon, M.-T. Delaye, and P. Berruyer: Proc. Micromachining and Microfabrication Process Technology VIII, SPIE 4979 (2003). https://doi.org/10.1117/12.478249

29 W. C. Welch III: Ph.D. Thesis, University of Michigan (2008). http://hdl.handle.net/2027.42/58520

30 M. S. Al Farisi, H. Hirano, and S. Tanaka: Sens. Actuators, A 279 (2018) 671. https://doi.org/10.1016/ j.sna.2018.06.021

31 V. Chidambaram, X. Ling, and C. Bangtao: J. Electron. Mater. 42 (2013) 485. https://doi.org/10.1007/s11664012-2350-9

32 I. P. Prikhodko, S. R. Brenton, G. Sharma, SA A. Zotov, A. Trusov, and A. M. Shkel: Proc. 46th Int. Symp. Microelectronics (IMAPS) (2013) 000705. https://imapsource.org/doi/10.4071/isom-2013-WP42

33 L. Mauri, E. Rizzi, M. Moraja, and M. Campaniello: Proc. European Microelectronics and Packaging Conference (EMPC) (2013) 1. https://ieeexplore.ieee.org/document/6698665

34 S. J. Kang, Y. S. Moon, W. H. Son, and S. Y. Choi: Jpn. J. Appl. Phys. 53 (2014) 066501. https://doi.org/10.7567/ JJAP.53.066501

35 C. D. Don, L. Jae-Wung, C. Bangtao, and N. Singh: Proc. IEEE 19th Electronics Packaging Technology Conf. (EPCT) (2017) 1. https://doi.org/10.1109/EPTC.2017.8277569

36 S. H. Choa: Microsyst. Technol. 11 (2005) 1187. https://doi.org/10.1007/s00542-005-0603-8

37 A. Hilton and D. S. Temple: Sensors 16 (2016) 1819. https://doi.org/10.3390/s16111819

38 H. M. Chu, T. Sasaki, and K. Hane: Microsyst. Technol. 24 (2018) 2159. https://doi.org/10.1007/s00542-017$3668-2$

39 C. Hurley, F. Martin, L. Marchetti, J. Chêne, C. Blanc, and E. Andrieu: Int. J. Hydrogen Energ. 40 (2015) p. 3402. https://doi.org/10.1016/j.ijhydene.2015.01.001

40 R. Ginham and A. Chew: Appl. Sci. Converg. Technol. 26 (2017) 95. https://doi.org/10.5757/ASCT.2017.26.5.95

41 A. W. Van Wieringen and N. Warmoltz: Physica 22 (1956) 849. http://doi.org/10.1016/S0031-8914(56)90039-8

42 W. G. Perkins: J. Vac. Sci. Technol. 10 (1973). 543 https://doi.org/10.1116/1.1318061

43 F. J. Norton: J. Appl. Phys. 28 (1957) 34. https://doi.org/10.1063/1.1722570

44 B. J. Mrstik, P. J. McMarr, N. S. Saks, R. W. Rendell, and R. B. Klein: Phys. Rev. B 47 (1983) 4115 https://doi. org/10.1103/PhysRevB.47.4115

45 D. Sparks, J. Mitchell, and S. Lee: J. Sens. Technol. 3 (2013) 101. https://doi.org/10.4236/jst.2013.34016

46 Z. Gan, D. Huang, X. Wang, D. Lin, and S. Liu: Proc. 10th IEEE Electronic Packaging Technology Conference (EPTC 2008) 755. https://doi.org/10.1109/EPTC.2008.4763523 
47 W. Reinert, D. Kahler, and G. Longoni: 7th IEEE Electronic Packaging Technology Conf. (EPTC 2005$) 225$. https://doi.org/10.1109/EPTC.2005.1614398

48 F. Gao, A. Hojkkanen, P. Pekko, A. KärkkaÏnen, and J. Kiihamäki: Phys. Procedia 32 (2012) 628. https://doi. org/10.1016/j.phpro.2012.03.610

49 B. Savornin, X. Baillin, E. Blanquet, I. Nuta, D. Saint-Patrice, P. Nicolas, P. J. Charvet, and J. L. Pornin: Proc IEEE Electronics Components Technol. Conf. (ECTC 2013) 1514. https://doi.org/10.1109/ECTC.2013.6575772

50 Q. Li, J. F. L. Goosen, J. T. M. van Beek, and G. Q. Zhang: Proc IEEE Int. Conf. Electronic Packaging Technology and High Density Packaging (IECEPT-HDP 2009) 802. https://doi.org/10.1109/ ICEPT.2009.5270637

51 B. Wang, S. Tanaka, B. Guo, G. Vereele, S. Severi, A. Witrouw, M. Wevers, and I. De Wolf: Microelectron. Rel. 51 (2011) 1878. https://doi.org/10.1016/j.microrel.2011.06.022

52 K. Saga and T. Hattori: J. Electrochem. Soc. 143 (1996) 3279. https://doi.org/10.1149/1.1837198

53 X. Liu, M. Adam, Y. He, and Y. Li: Proc. IEEE Particle Accelerator Conf. (PAC 2005) 2860. https://doi. org/10.1109/PAC.2005.1591294

54 M. Bender, H. Kollmus, M. C. Bellachioma, and W. Assmann: Nucl. Instrum. Methods Phys. Res., Sect. B 268 (2010) 1986. https://doi.org/10.1016/j.nimb.2010.02.114

55 O. B. Malyshev, R. Valizadeh, J. S. Colligon, A. Hannah, K. J. Middleman, S. Patel, and V. M. Vishnyakov: J. Vac. Sci. Technol., A 27 (2009) 521. https://doi.org/10.1116/1.3112623

56 Y. Li and S. Ho: Proc. IEEE Particle Accelerator Conf. (PAC 2003) 620-622. https://doi.org/10.1109/ PAC.2003.1288992

57 J. G. Bu, C. H. Mao, Y. Zhang, X. Y. Wei, and J. Du: J. Alloys Compd. 529 (2012) 69. https://doi.org/10.1016/ j.jallcom.2012.01.030

58 R. C. Kullberg and D. J. Rossiter: Proc. SPIE 6884, Reliability, Packaging, Testing, and Characterization of MEMS/MOEMS VII, 68840L. https://doi.org/10.1117/12.760823

59 C. Benvenuti, P. Chiggiato, A. Mongelluzzo, A. Prodromodes, V. Ruzinov, C. Scheuerlein, M. Taborelli, and F. Lévy: J. Vac. Sci. Technol., A 19 (2001) 2925. https://doi.org/10.1116/1.1414122

60 A. Bonucci, A. Conte, M. Moraja, G. Longoni, and M. Amiotti: Outgassing and Gettering in Handbook of Silicon-based MEMS Materials and Technologies (Elsevier, Oxford, 2010) 585. http://doi.org/10.1016/B978-08155-1594-4.00040-1

61 P.-L. Charvet, P. Nicolas, D. Bloch, and B. Savornin: Microelectron. Reliab. 53 (2013) 1622 https://doi. org/10.1016/j.microrel.2013.07.021

62 J. Cuomo and R. J. Gambino: J. Vac. Sci. Technol. 14 (1977) 152. https://doi.org/10.1116/1.569109

63 M. Wu, J. Moulin, S. Lani, G. Hallais, C. Renard, and A. Bosseboeuf: Jpn. J. Appl. Phys. 54 (2015) 030220. https://doi.org/10.7567/JJAP.54.030220

64 M. Wu, S. Lemettre, D. Mansour, M.-P. Plante, A. Bosseboeuf, S. Seok, and J. Moulin: IEEE Proc. Design Test, Integration and Packaging of MEMS/MOEMS (DTIP 2016). http://doi.org/10.1109/DTIP.2016.7514851

65 M. Wu, J. Moulin, P. Coste, S. Perrot, J.-L. Perrossier, C. Renard, and A. Bosseboeuf: Thin Solid Films 616 (2016) 543. https://doi.org/10.1016/j.tsf.2016.09.003

66 S. Lemettre, S. Hammami, A. Bosseboeuf, P. Coste, and J. Moulin: IEEE Proc. Design Test, Integration and Packaging of MEMS/MOEMS (DTIP 2017). http://doi.org/10.1109/DTIP.2017.7984502

67 M. Wu, J. Moulin, and A. Bosseboeuf: J. Appl. Phys. 124 (2018) 055301. http://doi.org/10.1063/1.5044570

68 M. Wu, J. Moulin, and A. Bosseboeuf: ECS J. Solid State Sci. Technol. 7 (2018) Q270. http://doi. org $/ 10.1149 / 2.0171812 \mathrm{jss}$

69 S. Lemettre, C. Bessouet, P. Coste, H. Lecoq, T. Sauvage, A. Bosseboeuf, and J. Moulin: ECS Trans. 86 (2018) 47. http://doi.org/ 10.1149/08616.0047ecst

70 ASTM Standard F798-97 (reapproved 2002). https://doi.org/10.1520/F0798-97R02

71 J. A. Dean: Lange's Handbook of Chemistry (MacGraw-Hill, New York, 1999) 4.6.

72 E. Fromm and G. Hörz: Int. Met. Rev. 25 (1980) 269. https://doi.org/10.1179/imtr.1980.2

73 A. Prodromides: Ph.D. Thesis, Ecole Polytechnique Fédérale de Lausanne (2002). http://inspirehep.net/ record/604752/files/thesis-2002-042.pdf

74 T. Heumann and H. Mehrer: Diffusion in Reinmetallen in Diffusion in Metallen (Springer-Verlag, Heidelberg, 1992) p. 103. https://doi.org/10.1007/978-3-642-86413-1 6

75 H. Wriedt: JPE 12 (1991) 170. https://doi.org/10.1007/BF02645713

76 H. H. Wu, P. Wisesa, and D. R. Trinkle: Phys. Rev. B 94 (2016) 014307. http://doi.org/10.1103/ physrevb.94.014307

77 H. Okamoto: J. Phase Equilib. Diffus. 29 (2008) 548. https://doi.org/10.1007\%2Fs11669-008-9393-x 
78 F. Šutara, T. Skàla, K. Mašek, and V. Maltolín: Vacuum 83 (2009) 824. https://doi.org/10.1016/ j.vacuum.2008.08.002

79 D. Petti, M. Cantoni, M. Leone, R. Bertacco, and E. Rizzi: Appl. Surf. Sci. 256 (2010) 6291. https://doi. org/10.1016/j.apsusc.2010.04.006

80 Z. Abboud and O. Moutanabbir: J. Phys. Chem. C 121 (2017) 3381. https://doi.org/10.1021/acs.jpcc.6b11426

81 A. Prodromides, C. Scheurlein, and M. Tarobelli: Appl. Surf. Sci. 191 (2002) 300. https://doi.org/10.1016/ S0169-4332(02)00222-2

82 L. Tenchine, X. Baillin, C. Faure, P. Nicolas, and E. Martinez: Procedia Eng. 5 (2010) 359. https://doi. org/10.1016/j.proeng.2010.09.122

83 E.-M. Bourim, H. Y. Kim, and N.-K. Chung: Micromachine 9 (2018) 490. https://doi.org/10.3390/mi9100490

84 R. Sirvinskaite, M. D. Cropper, A. N. Hannaj, O. B. Malyshev, and R. Valizadeh: Proc. Int. Particle Accelerator Conf. (IPAC 2018, JACoW ed.) 3869-3871. http://doi.org/10.18429/JACoW-IPAC2018-THPAL098

85 J. S. Foord, P. J. Goddard, and R. M. Lambert: Surf. Sci. 94 (1980) 339. https://doi.org/10.1016/00396028(80)90011-4

86 S. Lemettre, C. Bessouet, H. Lecoq, T. Sauvage, A. Bosseboeuf, P. Coste, and J. Moulin: Proc. Ion Beam Applications Francophone (IBAF) (2018) (in French).

87 S. Eickert, H. Hecht, and G. von Minnigerode: Z. Phys. B: Condens. Matter 88 (1992) 35. https://doi. org/10.1007/BF01573835

88 C. Bessouet, S. Lemettre, A. Bosseboeuf, P. Coste, H. Lecoq, T. Sauvage, and J. Moulin: IEEE Proc. Design Test, Integration and Packaging of MEMS/MOEMS (DTIP 2019) (accepted).

89 T. Miyazawa, M. Kurihara, S. Ohno, N. Terashima, Y. Natsui, H. Kato, A. Hashimoto, T. Kikuchi, and K. Mazse: J. Vac. Sci. Technol., A 36 (2018) 051601. https://doi.org/10.1116/1.5037023

90 M. Yoshitake and K. Yoshihara: Vacuum 51 (1998) 369. https://doi.org/10.1016/S0042-207X(98)00116-X

91 C. Benvenuti, P. Chiggiato, F. Cicoira, Y. L'Aminot, and V. Ruzinov: Vacuum 73 (2004) 139. https://doi. org/10.1016/j.vacuum.2003.12.022

92 T. Zhang, M. Zhang, R. Hu, H. Kou, J. Li, and X. Xue: Vacuum 122A (2015) 222. https://doi.org/10.1016/ j.vacuum.2015.10.007

93 T. Zhang, Y. Zhang, M. Zhang, R. Hu, H. Kou, J. Li, and X. Xue: Int. J. Hydrogen Energ. 41 (2016) 14778. https://doi.org/10.1016/j.ijhydene.2016.06.073

94 K. Chuntonov and J. Setina: Vacuum 123 (2016) 42. https://doi.org/10.4236/msce.2016.43004

95 A. H. Moghadam, V. Dashtizad, A. Kaflou, and H. Yoozbashitzadeh: Vacuum 111 (2015) 9. https://doi. org/10.1016/j.vacuum.2014.09.008

96 U. Narkiewicz, M. Podsiadły, R. Jędrzejewski, and I. Pełech: Appl. Catal. A Gal. 364 (2010) 27. https://doi. org/10.1016/j.apcata.2010.05.050

97 A. Lyapin, L. P. H. Jeurgens, and E. J. Mittemeijer: Acta Mater. 53 (2005) 2925. https://doi.org/10.1016/ j.actamat.2005.03.009

98 T. Smith: Surf. Sci. 38 (1973) 292. https://doi.org/10.1016/0039-6028(73)90163-5

99 C. V. Thomson: Ann. Rev. Mater. Res. 42 (2012) 399. https://doi.org/10.1146/annurev-matsci-070511-155048

100 A. Kosinova, O. Kovalenko, L. Klinger and E. Rabkin: Acta Mater. 83 (2015) 91. https://oi.org/10.1016/ j.actamat.2014.09.049

101 D. Gupta: Some Formal Aspects of Diffusion: Bulk Solids and Thin Films in Diffusion Phenomena in Thin Films Microelectronic Materials (Noyce Publication, Park Ridge, 1989) p. 1.

102 C. A. Handwerker: Diffusion-induced Grain Boundary Migration in Thin Film in Diffusion Phenomena in Thin Films Microelectronic Materials (Noyce Publication, Park Ridge, 1989) p. 245

103 C.-A. Chang: Effects of Ambients on Thin Film Interaction in Diffusion Phenomena in Thin Films Microelectronic Materials (Noyce Publication, Park Ridge, 1989) p. 323

104 R. K. Sharma, Jagannath, S. Bhattacharatya, S. C. Gadkari, R. Mukuni, and S. K. Gupta: J. Phys. Conf. Ser. 390 (2012) 012041. http://doi.org/10.1088/1742-6596/390/1/012041

105 J. Drbohlav, I. Matolinová, K. Masek, and V. Matolin: Vacuum 80 (2005) 47. https://doi.org/10.1016/ j.vacuum.2005.07.016

106 B. Erjavec and J. Setina: J. Vac. Sci. Technol., A 29 (2011) 051602. https://doi.org /10.1116/1.3626535

107 Ch. Day, X. Luo, X. Conte, A. Bonucci, and P. Manini: J. Vac. Sci. Technol., A 25 (2007) 824. https://doi. org/10.1116/1.2748799

108 T. K. Mehroff and L. W. Barnes: J. Vac. Sci. Technol., A 2 (1984) 1210. https://doi.org/10.1116/1.572705

109 H. Marom and T. Eizenberf: J. Appl. Phys. 96 (2004) 3319. https://doi.org/10.1063/1.1784552

110 G. Reiss, J. Vancea, and H. Hoffmann: Phys. Rev. Lett. 56 (1986) 2100. https://doi.org/10.1103/ PhysRevLett.56.2100 
111 M. A. Agandi: J. Mater. Sci. 20 (1985) 761. https://doi.org/10.1007/BF00585716

112 F. Lacy: Nanoscale Res. Lett. 6 (2011) 636. https://doi.org/10.1186/1556-276X-6-636

113 L. Moraga, C. Arenas, R. Henriquez, S. Barvo, and B. Solis: Physica B 499 (2016) 17. https://doi.org/10.1016/ j.physb.2016.07.001

114 A. E. Curzon and O. Singh: J. Phys. F: Met. Phys. 8 (1978) 1619. https://doi.org/10.1088/0305-4608/8/8/003

115 V. F. Gantmakher: JETP Lett. 94 (2011) 626. https://doi.org/10.1134/S0021364011200033

116 M. A. Howson and B. L. Gallagher: Phys. Rep. 170 (1988) 285. https://doi.org/10.1016/0370-1573(88)90145-7

117 J. Orbanič and I. Kokanovič: J. Non-Cryst. Solids 428 (1988) 31. https://doi.org/10.1016/j.jnoncrysol.2015.07.046

118 A. Regenbrecht: Ph.D. Thesis, University of Gottingen (1988).

\section{About the Authors}

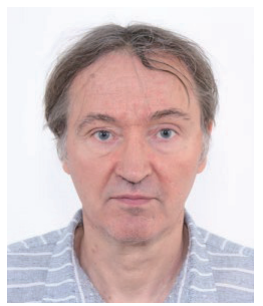

Alain Bosseboeuf received in 1980 an M.S. degree in microelectronics from INPG and a telecommunications engineer diploma from ENSTBr, in 1981 an M.S. degree in solid state physics from University of Paris 6, and in 1989 a state Ph.D. in physics from University Paris-Sud. Since 1984, he works as a full time CNRS researcher first in IEF/CNRS-University Paris-Sud and since June 2016 in C2N. His research interests are processes and characterization tools for thin films, MEMS, and WLP. (alain.bosseboeuf@c2n.upsaclay.fr)

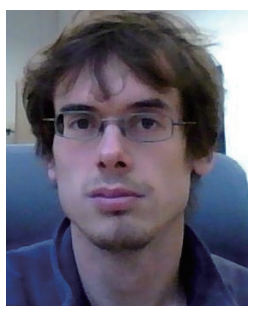

Sylvain Lemettre received an M.S. degree in engineering from the Institut National des Sciences Appliquées (INSA) of Toulouse, France, in 2014. He received his Ph.D. degree from University of Paris-Saclay in 2017. His research interests are in MEMS vacuum packaging.

(sylvain.lemettre@c2n.upsaclay.fr)

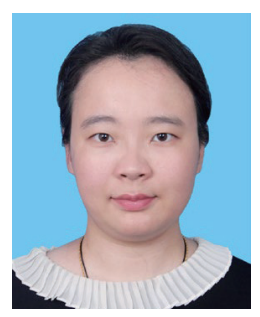

Ming Wu received her B.S. degree in communication engineering from Soochow University in China, her M.S. degree in micro- and nanotechnology from Lille 1 University, and her Ph.D. degree from University of ParisSud. She was an associate researcher at Soochow University and now she is working for Huawei Company. Her research activities are related to getter materials $(\mathrm{Zr}$, Ti, and $\mathrm{V})$, semiconductors, and radio frequency technology. (mingwu.lille@gmail.com)

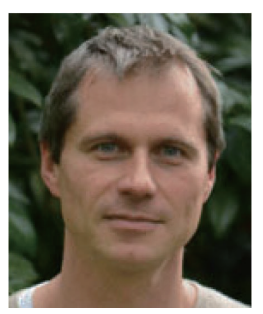

Johan Moulin received his M.S. and Ph.D. degrees in electrical engineering from the ENS de Cachan, France, in 1998 and 2001, respectively. He is an associate professor at University of Paris-Sud, Orsay since 2003 and his research activities are related to magnetic materials for MEMS, magnetic microsensors and actuators, and packaging for MEMS and getter materials. (johan.moulin@c2n.upsaclay.fr) 

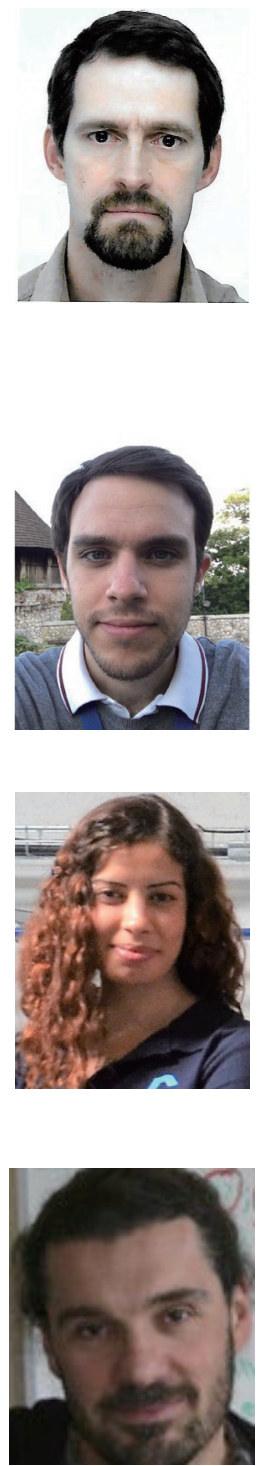

Philippe Coste received in 1985 an M.S. degree in electronics from University Paris-Sud and in 1991 a Ph.D degree in electronics from University Paris-Sud. Since 1991, he works as a senior lecturer first in IEF/CNRSUniversity Paris Sud and since June 2016 in C2N. His research interests are characterization tools for thin films, MEMS, and WLP.

(philippe.coste@c2n.upsaclay.fr)

Clément Bessouet received a B.S. degree in physical measurements at the University Institute of Technology of Paris-Jussieu in 2014 and an engineer degree in materials and nanotechnology at the Denis Diderot Engineering School (EIDD) of University Paris Diderot in 2017. He is currently pursuing a Ph.D. degree at $\mathrm{C} 2 \mathrm{~N}$ on new transition elements and rare-earth getter thin films for MEMS vacuum packaging. (clement.bessouet@c2n.upsaclay.fr)

Sana Hammami received in 2015 an M.S. degree in engineering from the Ecole Nationale d'Ingénieurs of Sfax, Tunisia, and in 2017 an M.S. degree in materials science from University of Paris-Saclay. She is currently working as a design engineer for CryoConcept, France, a company that produces highperformance dilution refrigerator systems.

(sana.hammami@cryoconcept.com).

Charles Renard received his Ph.D. degree in materials sciences from Denis Diderot University, Paris, France, in 2005. His Ph.D. work has been performed at Alcatel-Thales III-V Lab, where he was in charge of the development of quantum cascade lasers (QCLs) and detectors based on III-V materials by MBE. Since 2008, he has been a scientist researcher at C2N, where he is working on the growth of IV-IV materials on a Si substrate for hybrid integration. Since 2012, he has been enhancing the skills of the team by developing the epitaxial growth of III-V materials on $\mathrm{Si}$.

(charles.renard@c2n.upsaclay.fr).

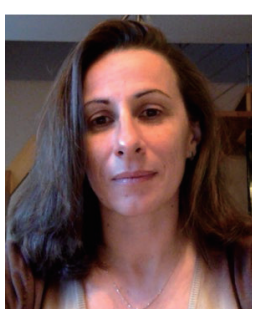

Laetitia Vincent received her Ph.D. in nuclear physics in 2001. She has worked for 10 years on implantation and irradiation-induced damage in semiconductors and nuclear ceramics. In 2010, she achieved a professional redirection and gained an expertise in the growth and comprehension of size effects in semiconductor NWs. Her research interests include growth mechanisms, doping, and properties of NWs. She has acquired a dual skill in structural TEM and ion beam characterization. Her methodology always relies on the study of relationship between structural and physical properties. (laetitia.vincent@c2n.upsaclay.fr) 